\title{
Identification of a bioactive core sequence from human laminin and its applicability to tissue engineering
}

In-Sung Yeo ${ }^{\mathrm{a}, 1}$, Seung-Ki Min ${ }^{\mathrm{b}, 1}$, Hyun Ki Kang ${ }^{\mathrm{c}}$, Taek-Ka Kwon ${ }^{\mathrm{d}}$, Sung Youn Jung ${ }^{\mathrm{c}}$, Byung-Moo $\mathrm{Min}^{\mathrm{c}, *}$

${ }^{a}$ Department of Prosthodontics, Seoul National University School of Dentistry, 101 Daehak-Ro, Jongno-Gu, Seoul 110-744, Republic of Korea

${ }^{\mathrm{b}}$ Department of Oral and Maxillofacial Surgery, Seoul National University School of Dentistry, 101 Daehak-Ro, Jongno-Gu, Seoul 110-744, Republic of Korea

${ }^{\mathrm{c}}$ Department of Oral Biochemistry and Program in Cancer and Developmental Biology and Dental Research Institute, Seoul National University School of Dentistry, 101 Daehak-Ro, Jongno-Gu, Seoul 110-744, Republic of Korea

${ }^{\mathrm{d}}$ Department of Dentistry, St. Vincent Hospital, Catholic University of Korea, Ji-Dong, Paldal-Ku, Suwon 442-723, Republic of Korea

${ }^{1}$ These authors contributed equally to this work.

${ }^{*}$ Corresponding author. Byung-Moo Min, Department of Oral Biochemistry and Program in Cancer and Developmental Biology, Seoul National University School of Dentistry, 101 Daehak-Ro, JongnoGu, Seoul 110-744, Republic of Korea. Tel.: +82 2740 8661. E-mail: bmmin@snu.ac.kr.

E-mail addresses: pros53@snu.ac.kr (I.-S. Yeo), snowmanonmars@gmail.com (S.-K. Min), kang1978@snu.ac.kr (H.K. Kang), tega95@naver.com (T.-K. Kwon), jsy1618@snu.ac.kr (S.Y.Jung), bmmin@snu.ac.kr (B.-M. Min). 


\begin{abstract}
Finding bioactive short peptides derived from proteins is a critical step to the advancement of tissue engineering and regenerative medicine, because the former maintains the functions of the latter without immunogenicity in biological systems. Here, we discovered a bioactive core nonapeptide sequence, PPFEGCIWN (residues 2678-2686; Ln2-LG3-P2-DN3), from the human laminin $\alpha 2$ chain, and investigated the role of this peptide in binding to transmembrane proteins to promote intracellular events leading to cell functions. This minimum bioactive sequence had neither secondary nor tertiary structures in a computational structure prediction. Nonetheless, Ln2-LG3-P2-DN3 bound to various cell types as actively as laminin in cell adhesion assays. The in vivo healing tests using rats revealed that Ln2-LG3-P2-DN3 promoted bone formation without any recognizable antigenic activity. Ln2LG3-P2-DN3-treated titanium (Ti) discs and Ti implant surfaces caused the enhancement of bone cell functions in vitro and induced faster osseointegration in vivo, respectively. These findings established a minimum bioactive sequence within human laminin, and its potential application value for regenerative medicine, especially for bone tissue engineering.
\end{abstract}

Keywords: Laminin; PPFEGCIWN motif; Bone formation; Osseointegration; Osteoblast differentiation 


\section{Introduction}

Complications, including graft rejection, donor site morbidity, and inadequate tissue formation, depending on the health status of each patient, limit current grafting methods to repair damaged tissues [1,2]. Tissue engineering is an exciting new approach that can overcome the limitations of tissue transplantation, providing man-made tissues to patients in need $[3,4]$. Several challenges have to be solved for a tissue-engineered material to be clinically applied; achieving appropriate functional activity without triggering an immune reaction is one of the most important goals. An example of an undesirable immune reaction is the recombinant human bone morphogenetic protein (rhBMP)-2, which is associated with early osteolysis, a kind of immunologic reaction, despite its enhanced bone formation effect $[5,6]$. The result is the sinking of an adjacent implanted material into the marrow [6]. Peptides are attractive as novel therapeutic reagents, since they are flexible in adopting and mimicking the local structural features of proteins. Their smaller molecular weight, synthetic versatility, and economical production mean that peptides share many drug targeting, potency, stability, and bioavailability challenges with other protein-based biological therapeutics such as antibodies and growth factors [7]. Finding short bioactive peptides is anticipated to overcome the obstacles that entire proteins have in regenerative medicine, because shorter amino acid sequences lower antigenicity [810]. A peptide found to have desirable bioactivity without immunogenicity is therefore fascinating in the field of tissue regeneration and regenerative medicine.

Laminins are major proteins in the basal lamina, a structural base for most cells and organs, and they contribute critically to cell adhesion, differentiation, and migration as well as tissue survival $[11,12]$. They are biologically active with a number of diverse cell types. A very interesting feature is that the cell functions of laminins are diverse, depending on cell types and cell-specific intracellular events $[11,13]$. This feature suggests that laminins and some derivative molecules should have the potential for broad applicability to the regeneration of various tissues. Structurally, laminins are trimeric proteins of an $\alpha$, a $\beta$, and a $\gamma$ chain that intersect to form a cross-like structure binding to some 
cell transmembrane molecules; this binding triggers intracellular events [14]. Laminin $\alpha$ chains contain a C-terminal large globular (LG) domain consisting of five globular modules (LG1-LG5) that are implicated as active regions for biological functions [11,15]. Specifically, the LG domains of the laminin $\alpha 2$ chain bind to the transmembrane molecules, integrins or syndecan- 1 , for the intracellular events and cell functions [15-18].

A bioactive short peptide would solve the immunologic reaction problem that every protein has by lowering antigenicity. Laminin has various biological effects according to cell type; intracellular events are promoted when the laminin binds to a membrane receptor. Therefore, if the core binding sequence of laminin is found and this short peptide is still bioactive for the cell functions, it will become a very useful tool for tissue regeneration and engineered tissue therapy with multiple desirable effects for each cell and tissue type with minimal immune reaction.

We previously found that the RNIPPFEGCIWN (residues 2675-2686; Ln2-LG3-P2) sequence within the human laminin $\alpha 2$ LG3 domain is a major ligand for $\alpha 3 \beta 1$ integrin, which mediates cell functions by inducing the membrane recruitment and phosphorylation of protein kinase $\mathrm{C} \delta(\mathrm{PKC} \delta)$ [17]. This study identified the minimum bioactive sequence that actively stimulated the intracellular events, and confirmed its applicability in the tissue engineering field by demonstrating that this peptide accelerated bone regeneration and healing without recognized side effects. 


\section{Materials and methods}

\subsection{Peptides, reagents, and preparation of titanium discs and implants}

All peptides were synthesized by the 9-fluorenylmethoxycarbonyl-based solid-phase method with a C-terminal amide on a Pioneer peptide synthesizer (Applied Biosystems, Foster City, CA, USA). Peptides were purified and characterized by Peptron (Daejeon, Korea). The purities of all of the peptides used in this study were greater than $95 \%$, as determined by high-performance liquid chromatography. The structures of the peptides were analyzed by the PSIPRED method for secondary structure prediction and by an ab initio technique for computational structure prediction $[19,20]$. Human placental laminin and bone morphogenetic protein (BMP)-2 were purchased from SigmaAldrich (St. Louis, MO, USA) and Pepro-Tech (Rocky Hill, NJ, USA), respectively. Titanium (Ti) discs (20 $\mathrm{mm}$ and $50 \mathrm{~mm}$ in diameter, $0.5 \mathrm{~mm}$ thick) and Ti implants ( $3.5 \mathrm{~mm}$ in diameter, $8 \mathrm{~mm}$ long) were prepared from commercially pure grade $4 \mathrm{Ti}$ (Warrantec, Seoul, Korea).

\subsection{Cell cultures and directed differentiation from skin-derived precursors to osteogenic cells}

The PC12 cell line from a transplantable rat pheochromocytoma was purchased from the American Type Culture Collection (ATCC; Rockville, MD, USA) and cultured in RPMI 1640 medium (BioWhittaker Cambrex, Walkersville, MD, USA) containing 10\% fetal bovine serum (FBS). The mouse embryo fibroblast cell line NIH/3T3, normal African green monkey kidney fibroblast cell line CV-1, and murine osteoblastic MC3T3-E1 cell line were purchased from the ATCC and cultured in Dulbecco's modified Eagle's medium (Gibco BRL, Carlsbad, CA, USA) containing 10\% FBS. For osteogenic differentiation, MC3T3-E1 cells were cultured in $\alpha$-minimal essential medium ( $\alpha$-MEM; Gibco BRL) supplemented with $0.1 \mu \mathrm{M}$ dexamethasone, $280 \mu \mathrm{M}$ ascorbic acid, $10 \mathrm{mM} \beta$-glycerol phosphate, and 10\% FBS for two weeks. The medium was changed every $2 \mathrm{~d}$, and cultures were 
maintained for two weeks without passaging. Primary normal human epidermal keratinocytes (NHEKs), normal human oral keratinocytes (NHOKs), normal human dermal fibroblasts (NHDFs), and normal human oral fibroblasts (NHOFs) were prepared and maintained as described previously $[21,22]$.

Human osteogenic cells were prepared and maintained as reported previously [23]. Briefly, for the directed differentiation of skin-derived sphere-forming cells into osteogenic cells, multipotent skin-derived precursors (SKPs) were isolated from the human foreskins of patients (1-3 years old) undergoing surgery $[24,25]$. Next, SKPs were differentiated into mesenchymal cells, as previously described [24]. Briefly, the tertiary spheres were dissociated into single cells with accutase and cultured in $\alpha$-MEM supplemented with $10 \%$ FBS. Attached cells were subcultured upon reaching $80 \%$ confluence, and third passage cells were used as SKP-derived mesenchymal cells. For osteogenic differentiation, SKP-derived mesenchymal cells were cultured in $\alpha$-MEM supplemented with $10 \mu \mathrm{M}$ dexamethasone, $200 \mu \mathrm{M}$ ascorbic acid, $10 \mathrm{mM} \beta$-glycerol phosphate, and 10\% FBS for two weeks. The medium was changed every $2 \mathrm{~d}$, and cultures were maintained for two weeks without passaging [24]. All procedures for obtaining human tissue specimens were performed in accordance with the guidelines of the Institutional Review Board on Human Subjects Research and the Ethics Committee at Seoul National University Dental Hospital, Seoul, Korea (approval number: CRI12004G).

\subsection{Cell adhesion, spreading, and migration assays}

Cell adhesion assays were performed as described previously [26]. Briefly, 24-well culture plates (Nunc, Roskilde, Denmark) were coated with bovine serum albumin (BSA; 1\%), human placental laminin $\left(1.1 \mu \mathrm{g} / \mathrm{cm}^{2}\right)$, recombinant LG3 $\left(\mathrm{rLG} 3 ; 5.7 \mu \mathrm{g} / \mathrm{cm}^{2}\right)$, and synthetic peptides $\left(11.4 \mu \mathrm{g} / \mathrm{cm}^{2}\right)$ by drying for $24 \mathrm{~h}$ at room temperature. The concentrations of the synthetic peptides were determined from a dose-response curve, and the lowest concentration necessary to achieve maximum adhesion to human osteogenic cells was used [17]. Substrate-coated plates were blocked with $1 \%$ heat-inactivated 
BSA in PBS for $1 \mathrm{~h}$ at $37{ }^{\circ} \mathrm{C}$ and were then washed with PBS. Cells were detached with trypsin/ethylenediaminetetraacetic acid (EDTA) and resuspended in serum-free culture medium. Cells $\left(1 \times 10^{5}\right.$ cells $\left./ 500 \mu \mathrm{l}\right)$ were added to a plate coated with peptide and incubated for $1 \mathrm{~h}$ for cell adhesion assays and $3 \mathrm{~h}$ for spreading assays at $37{ }^{\circ} \mathrm{C}$ in a $5 \% \mathrm{CO}_{2}$ atmosphere. After incubation, unattached cells were removed by rinsing the plates twice with PBS. Attached cells were fixed with $10 \%$ formalin in PBS for 15 min and then stained with $0.5 \%$ crystal violet for $1 \mathrm{~h}$. The plates were gently washed three times with double-distilled water (DDW), after which the contents of each well were solubilized in $2 \%$ sodium dodecyl sulfate (SDS) for $5 \mathrm{~min}$. Absorbance was measured at $570 \mathrm{~nm}$ with a microplate reader (Bio-Rad, Hercules, CA, USA). Similar cell adhesion assays were also performed with the Ln2-LG3-P2-DN3 motif $\left(11.4 \mu \mathrm{g} / \mathrm{cm}^{2}\right.$ ), NHEKs (passage 2), NHOKs (passage 2), NHDFs (passage 4), NHOFs (passage 4), human Schwann cells, MC3T3-E1, NIH/3T3, and CV-1 cells. For the cell spreading assays, cells $\left(3 \times 10^{4}\right.$ cells $\left./ 250 \mu \mathrm{l}\right)$ were added to each substrate-coated plate and incubated for $3 \mathrm{~h}$ at $37{ }^{\circ} \mathrm{C}$. Attached cells were fixed with $10 \%$ formalin and then stained with $0.5 \%$ crystal violet for $1 \mathrm{~h}$. Plates were gently washed three times with PBS. Cell spreading was assessed by measuring the surface areas of the cells with Image-Pro Plus software (Version 4.5; Media Cybernetics, Silver Spring, MD, USA). At least 200 cells were examined on each occasion. Cell migration assays were performed with transwell migration chambers (pore size, $8 \mu \mathrm{m}$; Corning, Pittston, PA, USA) as described previously [27]. Briefly, the lower side of each transwell filter was coated with laminin $\left(1.6 \mu \mathrm{g} / \mathrm{cm}^{2}\right), \mathrm{rLG} 3\left(7.9 \mu \mathrm{g} / \mathrm{cm}^{2}\right)$, or synthetic peptides $\left(19.7 \mu \mathrm{g} / \mathrm{cm}^{2}\right)$ by drying for $12 \mathrm{~h}$ at $4{ }^{\circ} \mathrm{C}$ (laminin) or for $24 \mathrm{~h}$ at room temperature (peptides). The lower sides of the transwell filters were blocked with $1 \%$ BSA in PBS for $1 \mathrm{~h}$ at $37^{\circ} \mathrm{C}$. Cells $\left(2 \times 10^{4}\right.$ cells $\left./ \mathrm{ml}\right)$ were suspended in $\alpha$-MEM containing $10 \mathrm{mM} \beta$-glycerol phosphate, $10 \mu \mathrm{M}$ dexamethasone, $200 \mu \mathrm{M}$ ascorbic acid, $0.5 \%$ FBS, and $0.1 \%$ BSA. This suspension $(100 \mu \mathrm{l})$ was seeded in the upper chamber of a transwell filter. Cells were allowed to migrate for $24 \mathrm{~h}$ at $37{ }^{\circ} \mathrm{C}$. Cells were then fixed with $10 \%$ formalin for $15 \mathrm{~min}$ and stained with $0.5 \%$ crystal violet. Unmigrated cells, those remaining in the upper side of the transwell filter, were removed with a cotton swab and counted under light microscopy. Cell migration 
was quantified by counting the number of cells that had migrated through the filter. Human placental laminin, rLG3, and Ln2-LG3-P2 were used as the positive controls and scrambled peptide (SP) was used as the negative control.

\subsection{Quantitative real-time polymerase chain reaction}

The mRNA levels of specific marker genes were determined by reverse transcription polymerase chain reaction (RT-PCR). Total RNA was isolated using the RNeasy Mini Kit (Qiagen, Valencia, CA, USA) according to the manufacturer's instructions. The RNA was denatured by incubation at $70{ }^{\circ} \mathrm{C}$ for $10 \mathrm{~min}$ and was kept on ice for $5 \mathrm{~min}$. The cDNA was then prepared using SuperScript ${ }^{\mathrm{TM}}$ III Reverse Transcriptase (Invitrogen, Carlsbad, CA, USA) and a random hexamer (Fermentas, Hanover, MD, USA) and was then subjected to real-time PCR amplification using SYBR ${ }^{\circledR}$ Premix Ex Taq $^{\mathrm{TM}}$ (Takara, Shiga, Japan) that contained a final concentration of $300 \mathrm{nM}$ for each primer and a quantity of cDNA corresponding to $133 \mathrm{ng}$ of total RNA. Quantitative real-time PCR (qRT-PCR) was performed using the 7300 Real-Time PCR System (Applied Biosystems). Primer sequences were designed using the Primer Express ${ }^{\circledR}$ Software version 3.0 (Applied Biosystems). The PCR primers used were as follows: alkaline phosphatase (ALP), 5'-CCCACGTCGATTGCATCTCT-3' (sense) and

5'-AGTAAGGCAGGTGCCAATGG-3' (antisense); bone sialoprotein (BSP), 5'-

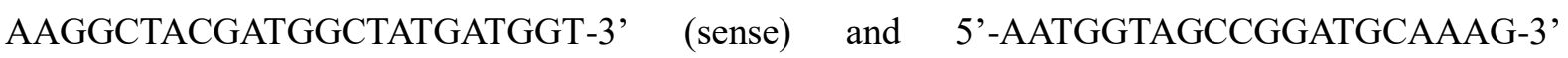
(antisense); type I collagen, 5'-CAAAAAATGGGAGACAATTTCACA-3' (sense) and 5'TCATGTTCGGTTGGTCAAAGAT-3' (antisense); RUNX2，5'-GCCTTCAAGGTGGTAGCCC-3' (sense) and 5'-CGTTACCCGCCATGACAGTA-3' (antisense); osteocalcin, 5'GAAGCCCAGCGGTGCA-3' (sense) and 5'-CACTACCTCGCTGCCCTCC-3' (antisense); osteonectin, 5'-TACATCGGGCCTTGCAAATAC-3' (sense) and 'GGGTGACCAGGACGTTCTTG-3' (antisense); and hypoxanthine phosphoribosyltransferase 1, 5'GGTCAGGCAGTATAATCCAAAGA-3' (sense) and 5'-GGGCATATCCTACAACAAACT-3' -8 - 
(antisense). After incubation at $95{ }^{\circ} \mathrm{C}$ for $30 \mathrm{~s}$, the PCR cycling conditions consisted of 40 cycles at 95 ${ }^{\circ} \mathrm{C}$ for $15 \mathrm{~s}, 60{ }^{\circ} \mathrm{C}$ for $20 \mathrm{~s}$, and $72{ }^{\circ} \mathrm{C}$ for $34 \mathrm{~s}$. To analyze the data, cycle threshold values were determined by automated threshold analysis with Sequenced Detection Software version 1.4 (Applied Biosystems), after which the calculated cycle threshold values were exported to Microsoft Excel for analysis. The relative expressions of each target mRNA were calculated using the comparative cycle threshold method according to the manufacturer's instructions (Applied Biosystems).

\subsection{Histological examination of inflammatory response in peptide-treated rats}

All murine experiments and procedures were performed according to protocols approved by the Animal Care Committee of the Institute of Laboratory Animal Resources of Seoul National University (approval number: SNU-130204-1). To determine the inflammatory response of the peptides, we used eight-week-old male Sprague-Dawley rats ( $n=3$ rats per group). All peptides (Ln2-LG3-P2-DN3 and Ln2-LG3-P2) were dissolved in dimethyl sulfoxide (DMSO) and then diluted with DDW. Absorbable collagen sponges (BiolandKorea, Cheonan, Korea) were cut out with a punch (8 $\mathrm{mm}$ in diameter), treated with peptides $\left(1.0 \mathrm{mg} / \mathrm{cm}^{2}, 15 \mu\right.$ volume $)$ or the vehicle alone (15 $\mu \mathrm{l}$ of DMSO), and dried for $24 \mathrm{~h}$ at room temperature. After each rat was anesthetized with an intraperitoneal injection of a Zoletil $50(31.3 \mathrm{mg} / \mathrm{kg})$ and Rompun $(9.9 \mathrm{mg} / \mathrm{kg})$ mixture, two full-thickness skin wounds were made on its back. Absorbable collagen sponges treated with the vehicle or peptides were applied to each wound and fixed with sutures. On the third day post-operation, the wounds were removed after euthanizing the rats. The harvested tissue was fixed, embedded in paraffin, sectioned, and stained with hematoxylin and eosin (H\&E). To ensure a representative sample, each wound sample was divided into quarters, and one field per quarter was sectioned and stained with H\&E.

\subsection{Animal experiments to evaluate new bone formation}


For critical-size calvarial defects, eight-week-old male Sprague-Dawley rats ( $n=4$ rats per group) were used. Ln2-LG3-P2-DN3 and SP were dissolved in DMSO and then diluted with DDW. Absorbable collagen sponges (BiolandKorea) were treated with recombinant human BMP-2 (4 $\mu \mathrm{g} / \mathrm{cm}^{2}, 15 \mu \mathrm{l}$ volume; Pepro-Tech) or peptides (0.5 and $1.0 \mathrm{mg} / \mathrm{cm}^{2}, 15 \mu 1$ volume). The surgical procedures for the creation of an 8-mm circular defect in the central parietal bone and implantation of the collagen sponge were carried out as described previously [28]. The rats were euthanized at three weeks after surgery, and whole calvaria were fixed in $4 \%$ paraformaldehyde for $24 \mathrm{~h}$ at $4{ }^{\circ} \mathrm{C}$ and then analyzed by micro-computed tomographic $(\mu \mathrm{CT})$ scanning. Details of the $\mu \mathrm{CT}$ scans are illustrated as described elsewhere. The specimens were then decalcified with 12\% EDTA for two weeks and embedded in paraffin. The paraffin-embedded samples were sectioned at a thickness of $6 \mu \mathrm{m}$ and stained with Masson's trichrome.

\subsection{Histomorphometric and $\mu C T$ analyses}

The $\mu \mathrm{CT}$ was performed with an SMX-90CT system $(90 \mathrm{kVp}, 109 \mathrm{~mA}$, and $180-\mathrm{ms}$ integration time; Shimadzu, Kyoto, Japan). Scans were integrated into three-dimensional voxel images $(1024 \times$ 1024 pixel matrices). All bone images were reconstructed by the VG Studio MAX 1.2.1 program

(Volume Graphics, Heidelberg, Germany) using standard procedures. The regenerated bone volume/tissue volume (\%) was calculated and expressed with TRI/3D-VIE (RATOC System Engineering, Kyoto, Japan) according to standard formulas and nomenclature. The bone recovery rate (\%) and calvarial thickness $(\mathrm{mm})$ were calculated with OsteoMeasure XP Version 1.01 (OsteoMetrics, Decatur, GA, USA) according to standardized protocols. 


\subsection{Scanning electron microscopy}

Pure Ti surfaces, without any modifications, were used in all experiments. Ti discs $(20 \mathrm{~mm}$ in diameter, $0.5 \mathrm{~mm}$ thick) were placed in 12-well plates (Nunc), with one disc per well. The culture plates containing the Ti discs were coated with BSA (1\%), human placental laminin $\left(1.4 \mu \mathrm{g} / \mathrm{cm}^{2}\right)$, or synthetic peptides $\left(14.3 \mu \mathrm{g} / \mathrm{cm}^{2}\right)$ by drying for $24 \mathrm{~h}$ at room temperature, then blocked with $1 \%$ heatinactivated BSA in PBS for $1 \mathrm{~h}$ at $37^{\circ} \mathrm{C}$, and finally washed with PBS. Cells $\left(2 \times 10^{5}\right.$ cells $\left./ \mathrm{ml}\right)$ were added to the Ti discs coated with peptides and incubated for $1 \mathrm{~h}$ at $37{ }^{\circ} \mathrm{C}$ in a $5 \% \mathrm{CO}_{2}$ atmosphere. After incubation, unattached cells were removed by rinsing the plates once with PBS. Attached cells were fixed with $10 \%$ formalin in PBS for 15 min and then stained with $0.5 \%$ crystal violet for $1 \mathrm{~h}$. The Ti discs were transferred to new 12-well plates and gently rinsed three times with DDW, after which the contents of each plate were solubilized in 2\% SDS for $5 \mathrm{~min}$. Absorbance was measured at $570 \mathrm{~nm}$ with a microplate reader (Bio-Rad).

Scanning electron microscopy (SEM) was used to examine the spreading of human osteogenic cells cultured onto the Ti surfaces. Cells $\left(1 \times 10^{5}\right.$ cells $\left./ 1 \mathrm{ml}\right)$ were added to each substrate-coated Ti disc and incubated for $3 \mathrm{~h}$ at $37{ }^{\circ} \mathrm{C}$. After incubation, unattached cells were removed by rinsing the plates once with PBS. Attached cells were fixed with 4\% paraformaldehyde in PBS for 15 min, and the fixative was then aspirated. After a buffer wash, the Ti discs were dehydrated in a graded series of ethanol solutions. After critical point drying (HCP-2, Hitachi, Tokyo, Japan), the samples were sputtered with Au/Pd using an SEM coating system (Quorum Q150T-S, Quorum Technologies, West Sussex, UK), and the probes were examined by field emission-SEM (FE-SEM; Hitachi S-4700, Hitachi) at $15 \mathrm{kV}$. To ensure a representative count, each Ti disc was divided into quarters and one field per quarter was photographed using FE-SEM and counted. 
The $60-\mathrm{mm}$ culture dishes containing the Ti discs ( $50 \mathrm{~mm}$ in diameter, $0.5 \mathrm{~mm}$ thick) were coated with SP, Ln2-LG3-P2, or Ln2-LG3-P2-DN3 $\left(14.3 \mu \mathrm{g} / \mathrm{cm}^{2}\right)$ by drying for $24 \mathrm{~h}$ in a vacuum at room temperature and were then washed once with PBS. Human osteogenic cells were detached with trypsin/EDTA and $3 \mathrm{ml}$ of a cell suspension containing $8 \times 10^{5}$ cells were placed on each Ti surface. The cells were cultured for $1 \mathrm{~d}$ at $37^{\circ} \mathrm{C}$ in a $5 \% \mathrm{CO}_{2}$ atmosphere. At the end of the incubation period, the Ti discs were transferred to new $60-\mathrm{mm}$ culture dishes. ALP activity was assayed in a reaction mixture composed of $8 \mathrm{mM}$ p-nitrophenyl phosphate (Calbiochem, San Diego, CA, USA), $0.1 \mathrm{M}$ glycine- $\mathrm{NaOH}$ buffer ( $\mathrm{pH} 10.4$ ), $150 \mathrm{mM} \mathrm{MgCl} 2,150 \mathrm{mM} \mathrm{ZnCl}$, and $15 \mu$ of cytosol in a final reaction volume of $90 \mu \mathrm{l}$. The reaction was incubated for $1 \mathrm{~h}$ in a water bath at $37^{\circ} \mathrm{C}$ and was terminated by the addition of $210 \mu \mathrm{l}$ of $0.25 \mathrm{~N} \mathrm{NaOH}$. The absorbance was measured at $405 \mathrm{~nm}$ in a Bio-Rad Model 550 microplate reader (Bio-Rad). Enzyme activity was expressed as nmol $p$ nitrophenol product per min per $\mu \mathrm{g}$ of protein.

\subsection{Animal experiments to evaluate osseointegration}

All rabbit experiments and procedures were performed according to protocols approved by the Animal Care Committee of the Institute of Laboratory Animal Resources of Seoul National University (approval number: SNU-111123-2). Pure, screw-shaped Ti implants (3.5 mm in diameter, $8 \mathrm{~mm}$ long) that were prepared from commercially pure grade $4 \mathrm{Ti}$ (Warrantec) were used without further surface modifications for the animal experiment. We used twelve male New Zealand white rabbits that ranged in age from one to two years old $(2.5-3.5 \mathrm{~kg})$. The rabbits showed no signs of disease. The anesthetic procedures, preparation of the surgical sites, and drilling for implant insertion were performed as described previously [29]. Drilling was done at the upper cortex only. The diameter of the holes drilled for implant insertion was $3.2 \mathrm{~mm}$. Forty-eight pure, screw-shaped Ti implants were used. Of 
the 48 implants, 12 were treated with SP, 12 were treated with Ln2-LG3-P2, and 12 were treated with Ln2-LG3-P2-DN3. The Ti implants were placed on 0.2-ml PCR tubes and coated with the peptides (1 $\mathrm{mg} / \mathrm{cm}^{2}$ ) by drying for $10 \mathrm{~d}$ in a vacuum at room temperature. To determine the coating efficiency of the peptides (Ln2-LG3-P2 and Ln2-LG3-P2-DN3) onto the Ti implant, peptide-coated Ti implants were transferred to new PCR tubes and washed twice for $15 \mathrm{~min}$ in DDW at room temperature. The amount of remaining peptide was determined using a $\mathrm{BCA}^{\mathrm{TM}}$ protein assay kit (Thermo Scientific, Rockford, IL, USA). The remaining 12 implants, which had pure Ti surfaces without further surface modifications, served as negative controls. Each rabbit received four implants, which included one from each of the four groups. Two implants were inserted in the right tibia and two implants were inserted in the left tibia. The implants were assigned according to a 4 x 4 Latin square (Suppl. Fig. 1). The implants penetrated the first cortical layer only. The periosteum and fascia were sutured with 4-0 chromic gut, and the skin was sutured with 4-0 silk (Ethicon, Somerville, NJ, USA).

\subsection{Histological assessment}

The animals were anesthetized and sacrificed by intravenous administration of potassium chloride for histomorphometry. Four rabbits were sacrificed at each of three time periods: one, two, and four weeks after implant insertion. The implants were surgically removed en bloc with an adjacent bone collar and immediately fixed in $4 \%$ neutral formaldehyde. The histomorphometric specimens were prepared as described previously [29]. The bone-to-implant contact (BIC) ratio was measured in the best three consecutive threads using a light microscope (Olympus BX microscope, Olympus, Tokyo, Japan) and image analysis software (Kappa Imagebase, Kappa Opto-electronics GmbH, Gleichen, Germany). The measurements were performed at $100 \times$ magnification.

In addition, the sections were stained using a modified Goldner's Masson trichrome staining technique and ALP histochemistry. We assayed collagen deposition using this technique, because it can detect collagen deposition on the undecalcified bone specimens [30]. Briefly, the sections were 
stained in Weigert hematoxylin for 20 min, washed in running water for 5 min, and rinsed in DDW. Then, the sections were stained in Blebrich scarlet-acid fuchsin solution for 20 min and placed in 1\% acetic acid solution for $5 \mathrm{~min}$. The slides were placed in phosphomolybdic-phosphotungstic acid solution for $5 \mathrm{~min}$ and then in $1 \%$ acetic acid solution for $3 \mathrm{~min}$. The sections were transferred into aniline blue solution for $5 \mathrm{~min}$ and placed in 1\% acetic acid solution. After being washed and dehydrated, the slides were examined at $100 \times$ magnification with a light microscope. New bone or osteoid is known to stain red using this method [30]. Next, ALP histochemistry was performed as described previously [31]. Briefly, the sections were stained in nitroblue tetrazolium chloride/5bromo-4-choloro-3-indolyl phosphate toluidine salt solution at $37{ }^{\circ} \mathrm{C}$ for $24 \mathrm{~h}$. The slides were counterstained with methyl green for 1 min and rinsed and examined at $200 \times$ magnification using the light microscope.

\subsection{Statistical analyses}

Statistical analyses were performed with the STATISTICA 6.0 software package (StatSoft, Tulsa, OK, USA). Results were compared with analysis of variance tests. When significant differences were found, pairwise comparisons were performed with Scheffe's adjustment. In the animal experiments, statistical analyses of BIC ratio data were performed with Kruskal-Wallis tests. $P$-values less than 0.05 were considered statistically significant. 


\section{Results}

\subsection{Identification of the bioactive core binding sequence in RNIPPFEGCIWN (Ln2-LG3-P2)}

To determine the minimum bioactive sequence, synthetic peptides were prepared from Ln2-LG3P2 (Fig. 1A), which are $\mathrm{N}$ - and $\mathrm{C}$-terminal truncated peptides and the combinations of both, and the cellular responses of PC-12 cells were examined on peptide-treated plates. The PPFEGCIWN motif (residues 2678-2686; Ln2-LG3-P2-DN3), which has a deletion of the N-terminal RNI residues in Ln2-LG3-P2, significantly promoted cell adhesion activity with similar contents to human placental laminin and Ln2-LG3-P2 (Fig. 1B). The levels of cell spreading and migration of the peptide did not significantly differ between Ln2-LG3-P2-DN3 and the positive controls (rLG3 and Ln2-LG3-P2) (Fig. 1C and D). The cell spreading and migration activities of Ln2-LG3-P2-DN3 were evaluated to be approximately $57 \%$ and $43 \%$ of those of the laminin, respectively. Further deletion of the N-and Cterminal residues in Ln2-LG3-P2-DN3 led to significantly lower cellular responses than that of Ln2LG3-P2-DN3 (Fig. 1B-D).

Because Ln2-LG3-P2-DN3 displayed cell adhesion activity in PC-12 cells, we further investigated whether Ln2-LG3-P2-DN3 would mediate the adhesion of other types of cells. Ln2-LG3-P2-DN3 at $11.4 \mu \mathrm{g} / \mathrm{cm}^{2}$ displayed strong cell adhesion activity to NHEKs, NHOKs, NHDFs, NHOFs, human Schwann cells, MC3T3-E1, NIH/3T3, and CV-1 cells (Fig. 1E), demonstrating a broad cell-type specificity of adhesion. Computations for the peptide structures predicted no specific secondary or tertiary structure for either Ln2-LG3-P2-DN3 or Ln2-LG3-P2 (data not shown). Taken together, these results indicate that the Ln2-LG3-P2-DN3 motif within the human laminin $\alpha 2$ LG3 domain is the bioactive core binding sequence without a specific conformational structure, which is important for the cellular responses of various cell types. 


\subsection{Effects of Ln2-LG3-P2-DN3 motif on osteogenic cellular responses}

To confirm that Ln2-LG3-P2-DN3 promoted cellular responses in PC-12 cells, this study used SKPs obtained from human foreskin and verified their differentiation to mesenchymal cells and then to osteogenic cells. The differentiated osteogenic cells formed aggregates or nodules, and calcium accumulation was evident after two weeks. Alizarin red S staining demonstrated that mineral deposits were associated with some of these nodules. These mineral deposits were abundant at two weeks and were localized both to cells in the nodules and to some cells that grew in monolayers (Fig. 2A). In addition, qRT-PCR analysis revealed a $\sim 74$-fold increase in $A L P$ expression in the differentiated osteogenic cells compared to the SKP-derived mesenchymal cells (Fig. 2B). Next, we assessed the expression of osteogenic markers [22], including osteonectin, type I collagen, BSP, RUNX2, and osteocalcin. The expression levels of the osteogenic markers tested were significantly upregulated in the differentiated cells (Fig. 2B). These results clearly indicate that the SKP-derived cells differentiated into an osteogenic lineage. In the following experiments, these differentiated osteogenic cells were used as human osteogenic cells.

The adhesion of human osteogenic cells and osteoblast-like cells was evaluated using a cell adhesion assay in serum-free medium. Ln2-LG3-P2-DN3 and one of its mother molecules, Ln2-LG3P2, significantly promoted the cell adhesion of osteogenic cells and osteoblast-like HOS and MG63 cells as compared with the SP-treated controls (Fig. 2C and D; Suppl. Fig. 2A and B). Culture plates coated with Ln2-LG3-P2-DN3 and Ln2-LG3-P2 showed significantly higher cell spreading of osteogenic cells and osteoblast-like cells than did those treated with SP (Fig. 2E; Suppl. Fig. 2C). Ln2-LG3-P2-DN3 significantly induced ALP activity compared with the vehicle control, although ALP activity in Ln2-LG3-P2-DN3 was lower than that was observed in rhBMP2 (Fig. 2F). These results support the hypothesis that Ln2-LG3-P2-DN3 is functionally active in promoting osteoblastic responses, which are important for bone formation and healing. 


\subsection{Effects of the Ln2-LG3-P2-DN3 motif on antigenicity}

Because the inflammatory response is one of the most important factors for early-stage wound healing using tissue-engineering approaches [32], the inflammatory responses during early-stage wound healing were compared in rats transplanted with absorbable collagen sponges treated with vehicle or peptides. In the vehicle-treated rats, inflammatory cells consistently infiltrated into the tissues adjacent to the inner surfaces of the absorbable collagen sponges (Fig. 3A and B). The number of infiltrating inflammatory cells in both Ln2-LG3-P2-DN3- and Ln2-LG3-P2-treated rats was similar to that in the vehicle-treated rats (Fig. 3A and B). There were no multinucleated foreign body giant cells in either the vehicle- or peptide-treated rats. These findings confirm that Ln2-LG3-P2-DN3 has low or no antigenicity.

\subsection{Effects of Ln2-LG3-P2-DN3 motif on healing of bone defects}

To investigate whether Ln2-LG3-P2-DN3 promotes the osteogenic capacity to repair bone defects in vivo, the critical-size calvarial defect model in rats was used. The $\mu \mathrm{CT}$ images of the calvarial defects demonstrated that the SP-treated rats showed limited new bone formation at the defect sites three weeks after surgery, whereas the Ln2-LG3-P2-DN3-treated rats showed significant bone healing. The amounts of newly generated bone in the rats treated with 0.5 and $1.0 \mathrm{mg} / \mathrm{cm}^{2}$ of Ln2-LG3-P2DN3 were significantly increased compared with the SP-treated controls (Fig. 4A). Quantitative bone morphometric analyses revealed that Ln2-LG3-P2-DN3 increased both bone area (Fig. 4B) and volume (Fig. 4C). Masson's trichrome-stained histologic sections and quantitative histomorphometry for calvarial thickness confirmed greater amounts of bone regeneration in the Ln2-LG3-P2-DN3treated rats than in the SP-treated controls (Fig. 4D and E). These results demonstrate that Ln2-LG3$\mathrm{P} 2-\mathrm{DN} 3$ promotes new bone formation in vivo. 


\subsection{Effects of Ln2-LG3-P2-DN3-treated Ti surfaces on cellular responses and ALP activities}

The osteogenic potential of Ln2-LG3-P2-DN3 was evaluated in vitro when the peptide was applied on Ti surfaces. Osteogenic cell adhesion, spreading, and ALP activity were investigated on Ti surfaces treated with Ln2-LG3-P2-DN3 and Ln2-LG3-P2, because the initial contact and responses of the osteoblasts with the implant surfaces are an important event for implant osseointegration [23]. The adhesion and spreading of osteogenic cells on Ln2-LG3-P2-DN3- and Ln2-LG3-P2-treated Ti surfaces were significantly greater than on the BSA- or SP-treated controls (Fig. 5A and C). The adhesion of osteoblast-like HOS and MG-63 cells on Ln2-LG3-P2-DN3- and Ln2-LG3-P2-treated Ti surfaces was similar to even that of laminin (Suppl. Fig. 3A and B). The spreading of HOS and MG63 cells on the Ln2-LG3-P2-DN3- and Ln2-LG3-P2-treated Ti surfaces displayed a similar pattern to that of human osteogenic cells (Suppl. Fig. 3C). To assess the osteogenic potential of the peptides, the expression levels of osteogenic markers were determined in human osteogenic cells seeded onto Ln2LG3-P2-DN3- and Ln2-LG3-P2-treated Ti surfaces after $3 \mathrm{~d}$ by qRT-PCR analysis. The expression levels of osteonectin, type I collagen, RUNX2, and osteocalcin were significantly higher in the osteogenic cells on Ln2-LG3-P2- and Ln2-LG3-P2-DN3-treated Ti surfaces than in those on the untreated and SP-treated surfaces (Fig. 5D). Furthermore, the effects of peptides on ALP activity were investigated, because increased ALP activity is a well-known indicator for osteoblast differentiation [24,25], implicating an increased bone forming response at the protein level. Human osteogenic cells seeded onto the Ln2-LG3-P2-DN3-treated Ti surfaces for $1 \mathrm{~d}$ showed significantly higher ALP activity not only than the negative controls (the untreated and SP-treated Ti surfaces), but also than the positive control, the Ln2-LG3-P2-treated surface (Fig. 5E). These results demonstrate that Ti surfaces treated with Ln2-LG3-P2-DN3 were functionally active in promoting osteogenic cellular responses.

\subsection{Effects of Ln2-LG3-P2-DN3 on implant osseointegration}


The osteogenic potential of Ln2-LG3-P2-DN3 was further assessed in vivo using the rabbit tibia model and the Ln2-LG3-P2-DN3-treated Ti implants, which had the clinically applicable shape and dimensions. Because synthetic peptides that mimic extracellular matrix proteins function via signal transduction through cell membrane receptors $[16,26]$, the amount of peptides applied onto scaffolds is important for their biological function. Therefore, the coating efficiency of the peptides onto the Ti implants was determined; approximately $85.9 \%$ of the peptides were coated onto the Ti implants after dry coating (data not shown). There was no inflammation of the bone near the inserted implants at the time of sacrifice in the experimental animals. In light microscopy, no inflammatory cells or multinucleated foreign body giant cells were found around the implants (Fig. 6A).

Newly formed cancellous bone was found between the threads of the Ln2-LG3-P2-DN3- and Ln2LG3-P2-treated implants at one week after implant insertion, while little new bone was found in the pure Ti and SP-treated implants (Fig. 6A, upper). More cancellous bone had formed after two weeks of healing, with new bone tissue slowly forming in the pure Ti and SP-treated implants (Fig. 6A, middle). New cortical bone was formed in all groups at four weeks after implant placement, and the mature bone was anchored to the implant surface (Fig. 6A, lower). Fig. 6B shows the BIC ratio in each group. Whether the implant was installed on the right or left side did not affect the results (data not shown). As expected, the healing period affected the BIC ratio, with longer healing times corresponding to higher BIC ratios (Fig. 6B). The pure Ti and SP-treated implants had the lowest BIC ratios throughout the experimental period after implant insertion; the Ln2-LG3-P2-DN3-treated implant showed significantly higher BIC ratio than the pure Ti and SP-treated implants did after both one and four weeks of healing (Fig. 6B). Similarly, the Ln2-LG3-P2-DN3-treated implant had a tendency toward more favorable bone response after two weeks of healing than the pure Ti and SPtreated implants despite of no statistically significant differences in BIC (Fig. 6B).

To confirm new bone formation around the implants, collagen deposition was determined in the threads of the implant using modified Goldner's Masson trichrome staining, which is an appropriate 
bone stain because it provides good distinction of newly formed osteoid, which stains red [21]. Considerable collagen deposition was found between the threads of the Ln2-LG3-P2-DN3- and Ln2LG3-P2-treated implants two weeks after implant insertion, while little collagen deposition was formed in the pure Ti and SP-treated implants (Fig. 6C). After four weeks of healing, similar amounts of collagen deposition were found in all four implant groups (Fig. 6C).

To detect osteoblasts in the transplanted site, ALP histochemistry was used. ALP expression was markedly increased in Ln2-LG3-P2-DN3- and Ln2-LG3-P2-treated implants compared with the other implants after one week of healing (Fig. 6D). ALP expression was more definitive in the Ln2-LG3P2-DN3- and Ln2-LG3-P2-treated implants compared with that in the pure Ti and SP-treated implants (Fig. 6D, middle and right). Taken together, these results demonstrated that Ln2-LG3-P2-DN3 and Ln2-LG3-P2 had a strong osteogenic effect in early-stage osseointegration by promoting collagen deposition and ALP expression. 


\section{Discussion}

This study identified the minimum bioactive sequence, the PPFEGCIWN motif, for cell adhesion from the active sites of the laminin $\alpha 2$ chain. It also demonstrated the biological activities and effects of Ln2-LG3-P2-DN3 on tissue regeneration, especially bone regeneration, which had not been previously studied. Furthermore, this study showed that this minimum bioactive sequence with nine amino acids was significantly higher in ALP activity than Ln2-LG3-P2, the original sequence with 12 amino acids, was. These findings are highly meaningful because initial cell adhesion and spreading play an important role in early-stage wound healing, and because bioactive peptides are recognized as valuable scientific tools in the field of tissue engineering due to their ability to improve the functional activity of the scaffold and to bypass or minimize immune rejection [23,30,33]. The comparison with the vehicle control and rhBMP-2 clearly indicated the bone forming capability of this peptide. rhBMP-2 is considered to be stronger in bone formation because it is a cytokine directly switching on the bone forming mechanism. However, rhBMP-2 is inapplicable on the implant surface due to uncoatability on the Ti surface, and no contribution to the cell adhesion. The Ln2-LG3-P2-DN3 motif acted as an effective bioactive peptide for bone formation and osseointegration, especially by stimulating osteoblast differentiation through increased ALP activity or expression.

To date, Ln2-LG3-P2-DN3 is the only active site that displays biological functions within the human laminin $\alpha 2$ LG3 domain. The Ln2-LG3-P2-DN3 sequence within the LG3 domain was located in the connecting loop of the $\mathrm{K}$ and $\mathrm{L}$ strands of the human laminin $\alpha 2$ chain [17]. This is partially consistent with a previous report [31] showing that alignment of LG sequences was localized to the GD-6 peptide (KQNCLSSRASFRGCVRNLRLSR, residues 3011-3032) from the C-terminal LG domain of the murine laminin $\alpha 1$ chain to a region between the K-L and L-M loops of the mouse laminin $\alpha 1$ chain, which we found to be in the connecting loop between the K and L strands of the human laminin $\alpha 2$ chain. However, Ln2-LG3-P2-DN3 itself, a sequence of only nine amino acids, was interpreted to have no specific conformational structure from the computational structure 
prediction algorithm used in this study. Nonetheless, this non-structural sequence of nine amino acids was evaluated to be effective enough to provoke the intracellular events with approximately $104 \%$, $57 \%$, and $43 \%$ of the activity of its mother protein, laminin, in cell adhesion, spreading, and migration activities, respectively. Determined to be a bioactive core sequence for cellular responses in PC12 cells, Ln2-LG3-P2-DN3 was shown to have effective cellular responses in a broad range of cell types, including osteoblasts, which indicated the potential for the biomedical application of this peptide. The Ln2-LG3-P2-DN3 sequence, PPFEGCIWN, was considered to use the phosphorylation of PKC $\delta$ for the intracellular events, similar to the Ln2-LG3-P2 sequence, RNIPPFEGCIWN [17]. Also, another functional peptide derived from the LG1 domain of the human laminin $\alpha 2$ chain, DLTIDDSYWYRI, was previously shown to trigger the intracellular events via $\mathrm{PKC} \delta$ phosphorylation [16]. A new hypothesis, based on a recent summary for allostery, may unify those results (Fig. 7) [34]. There would be various conformational energy states when the functional peptides or the protein bind to the transmembrane proteins that have tunable sensitivity for PKC $\delta$ phosphorylation. PPFEGCIWN and DLTIDDSYWYRI bind to the receptors, stabilize the conformations, increase the probabilities of the active states, and effectively trigger the intracellular events via $\alpha 3 \beta 1$ integrin and syndecan-1, respectively, although those peptides are not as active as the laminin. This hypothesis explains how such non-structural functional peptides exert their effects.

Considering that the final goal of peptide development is biomedical application, and several challenges, such as the risk of immunogenicity of peptide-treated scaffolds, should first be overcome, the antigenicity of the peptides and their effects on the inflammatory phase of wound healing must be investigated. Thus, this study examined the antigenicity and/or inflammatory response to the scaffolds treated with the peptides in full-thickness skin wounds. In this study, Ln2-LG3-P2-DN3, a short synthetic nonapeptide that was identified as a biologically active core sequence, showed no significant differences in the number of infiltrating inflammatory cells as compared to the vehicle. In addition, there were no multinucleated foreign body giant cells found. These results are consistent with previous reports demonstrating that bioactive short peptides induce cellular responses without 
immunoreactivity [21,30,32,35]. Although functions and potential applications of several proteins have been presented, the use of macromolecules for therapeutics is associated with many disadvantages, such as poor bioavailability, the neutralization of antibody production, low stability, and a risk of severe side effects from the antigen-antibody reaction. They also have cost and insurance issues stemming from their high expense [36]. Peptides can potentially offer effective treatments that are able to address these issues, because they are small molecules and can be produced by fully synthetic chemical methods instead of by biological purification [7]. Our findings indicated that Ln2LG3-P2-DN3 may have low or no antigenicity, which makes the PPFEGCIWN motif promising in the field of tissue engineering and regenerative medicine, because a protein, like a laminin itself, is usually an antigen.

The potential roles of the Ln2-LG3-P2-DN3 motif in tissue regeneration were further investigated in this study. Concretely, bone formation and the healing effects of this peptide were evaluated both in vitro and in vivo. The enhanced responses of human osteogenic cells were confirmed in vitro, and such results were consistently shown in vivo without inducing host immune responses. The experiment using the critical-size rat calvarial defect model showed that Ln2-LG3-P2-DN3 significantly promoted new bone formation by enhancing bone volume, area, and thickness. The applicability of this peptide was also estimated in this study by using it to coat $\mathrm{Ti}$, which is the most widely used material in orthopedic implants and dental endoprostheses. The improved indices, implying advanced bone healing, were found in vitro on the Ln2-LG3-P2-DN3-treated Ti surface; we found enhanced bone cell attachment and spreading, heightened gene expression of osteogenic markers, and increased ALP activity of osteogenic cells. Also, the promising results were shown in the in vivo experiment, which used the rabbit tibia model and the Ln2-LG3-P2-DN3-treated Ti implants without blocking that is more appropriate than implants with blocking for use in clinical contexts [37]. Accelerated bone responses were confirmed around the peptide-treated implants both quantitatively (BIC ratio) and qualitatively (modified Goldner's Masson trichrome staining of collagen and ALP histochemistry of osteoblasts). These findings are consistent with those of previous 
studies reporting that the modification of biomaterials with bioactive peptides derived from extracellular matrix proteins led to new bone formation by increasing cell adhesion, osteoblast differentiation and biomineralization [38], and that laminin-treated ceramic scaffolds activated osteogenesis by promoting the adhesion of osteoprogenitor cells $[39,40]$. Considering those results regarding bone healing and the broad cell-type affinity of this peptide, the PPFEGCIWN motif has great potential for various tissue engineering and biomedical applications.

In summary, this study identified a bioactive core binding sequence, PPFEGCIWN, within the human laminin $\alpha 2$ chain. This motif showed an affinity for various cell types, including the cells that originated from the epithelium and from the connective tissue. Ln2-LG3-P2-DN3 promoted new bone formation in vivo with low or no antigenicity. The PPFEGCIWN-treated surface displayed a strong osteogenic effect in dental and orthopedic implant therapy regimens by stimulating osteoblast differentiation through increased ALP activity or expression, thus promoting osseointegration between the host bone and the implant surface. These results demonstrated the potential therapeutic value of the PPFEGCIWN motif for biomedical applications, especially for bone tissue engineering applications. 


\section{Conclusions}

Our findings show that the PPFEGCIWN motif, which was identified as a biologically active core-binding sequence within the human laminin $\alpha 2$ chain, promoted cell adhesion and spreading of human osteogenic cells and osteoblast-like cells in the cytocompatibility assessment. Pure Ti surfaces treated with Ln2-LG3-P2-DN3 were functionally active in increasing ALP activity and osteogenic marker gene expression, as well as promoting cellular responses of human osteogenic cells. An assessment of bone formation revealed that the Ln2-LG3-P2-DN3 was effective in promoting bone formation by enhancing the bone area, bone volume, and thickness in critical-size rat calvarial defects. The application of the Ln2-LG3-P2-DN3-treated Ti implants to rabbit tibia wounds significantly promoted osseointegration by enhancing the BIC ratio, indicating that Ln2-LG3-P2-DN3 could improve the biological performance of Ti implants and reduce the time required before the loading of loadbearing, bone contacting devices.

\section{Acknowledgments}

This work was supported by the Mid-career Researcher Program through a National Research Foundation grant (2013R1A2A2A05004267) funded by the Korean Ministry of Education, Science and Technology and the Korea Healthcare Technology R\&D Project (H112C0913), Ministry for Health, Welfare \& Family Affairs, Republic of Korea to B-MM.

\section{References}


[1] Wiesmann HP, Joos U, Meyer U. Biological and biophysical principles in extracorporal bone tissue engineering. Part II. Int J Oral Maxillofac Surg 2004;33:523-30.

[2] Yaszemski MJ, Payne RG, Hayes WC, Langer R, Mikos AG. Evolution of bone transplantation: molecular, cellular and tissue strategies to engineer human bone. Biomaterials 1996;17:175-85.

[3] Griffith LG, Naughton G. Tissue engineering-current challenges and expanding opportunities. Science 2002;295:1009-14.

[4] Langer R, Vacanti JP. Tissue engineering. Science 1993;260:920-6.

[5] Comer GC, Smith MW, Hurwitz EL, Mitsunaga KA, Kessler R, Carragee EJ. Retrograde ejaculation after anterior lumbar interbody fusion with and without bone morphogenetic protein-2 augmentation: a 10-year cohort controlled study. Spine J 2012;12:881-90.

[6] Kang JD. Another complication associated with rhBMP-2? Spine J 2011;11:517-9.

[7] Aoki K, Alles N, Soysa N, Ohya K. Peptide-based delivery to bone. Adv Drug Deliv Rev 2012;64:1220-38

[8] Lee JY, Choi YS, Lee SJ, Chung CP, Park YJ. Bioactive peptide-modified biomaterials for bone regeneration. Curr Pharm Des 2011;17:2663-76.

[9] Molek P, Strukelj B, Bratkovic T. Peptide phage display as a tool for drug discovery: targeting membrane receptors. Molecules 2011;16:857-87.

[10] Slingluff CL. The present and future of peptide vaccines for cancer: single or multiple, long or short, alone or in combination? Cancer J 2011;17:343-50.

[11] Colognato H, Yurchenco PD. Form and function: the laminin family of heterotrimers. Dev Dyn $2000 ; 218: 213-34$

[12] Timpl R, Rohde H, Robey PG, Rennard SI, Foidart JM, Martin GR. Laminin-a glycoprotein from basement membranes. J Biol Chem 1979;254:9933-7.

[13] Domogatskaya A, Rodin S, Tryggvason K. Functional diversity of laminins. Annu Rev Cell Dev Biol 2012;28:523-53.

[14] Haralson MA, Hassell, JR. Extracellular matrix : a practical approach. Oxford : IRL Press Ltd.; $-26-$ 
1995.

[15] Suzuki N, Yokoyama F, Nomizu M. Functional sites in the laminin alpha chains. Connect Tissue Res 2005;46:142-52.

[16] Jung SY, Kim JM, Kang HK, Jang da H, Min BM. A biologically active sequence of the laminin $\alpha 2$ large globular 1 domain promotes cell adhesion through syndecan-1 by inducing phosphorylation and membrane localization of protein kinase $\mathrm{C} \delta$. J Biol Chem $2009 ; 284: 31764-75$.

[17] Jung SY, Kim JM, Min SK, Kim OB, Jang da H, Kang HK, et al. The potential of laminin-2biomimetic short peptide to promote cell adhesion, spreading and migration by inducing membrane recruitment and phosphorylation of PKC $\delta$. Biomaterials 2012;33:3967-79.

[18] Vuolteenaho R, Nissinen M, Sainio K, Byers M, Eddy R, Hirvonen H, et al. Human laminin M chain (merosin): complete primary structure, chromosomal assignment, and expression of the M and A chain in human fetal tissues. J Cell Biol 1994;124:381-94.

[19] Jones DT. Protein secondary structure prediction based on position-specific scoring matrices. J Mol Biol 1999;292:195-202.

[20] Raman S, Vernon R, Thompson J, Tyka M, Sadreyev R, Pei J, et al. Structure prediction for CASP8 with all-atom refinement using Rosetta. Proteins 2009;77 Suppl 9:89-99.

[21] Min BM, Lee G, Kim SH, Nam YS, Lee TS, Park WH. Electrospinning of silk fibroin nanofibers and its effect on the adhesion and spreading of normal human keratinocytes and fibroblasts in vitro. Biomaterials 2004;25:1289-97.

[22] Yeo IS, Oh JE, Jeong L, Lee TS, Lee SJ, Park WH, et al. Collagen-based biomimetic nanofibrous scaffolds: preparation and characterization of collagen/silk fibroin bicomponent nanofibrous structures. Biomacromolecules 2008;9:1106-16.

[23] Kang HK, Min SK, Jung SY, Jung K, Jang da H, Kim OB, et al. The potential of mouse skinderived precursors to differentiate into mesenchymal and neural lineages and their application to osteogenic induction in vivo. Int J Mol Med 2011;28:1001-11. 
[24] Fernandes KJ, McKenzie IA, Mill P, Smith KM, Akhavan M, Barnabe-Heider F, et al. A dermal niche for multipotent adult skin-derived precursor cells. Nat Cell Biol 2004;6:1082-93.

[25] Toma JG, Akhavan M, Fernandes KJ, Barnabe-Heider F, Sadikot A, Kaplan DR, et al. Isolation of multipotent adult stem cells from the dermis of mammalian skin. Nat Cell Biol 2001;3:77884.

[26] Kim JM, Park WH, Min BM. The PPFLMLLKGSTR motif in globular domain 3 of the human laminin-5 $\alpha 3$ chain is crucial for integrin $\alpha 3 \beta 1$ binding and cell adhesion. Exp Cell Res 2005;304:317-27.

[27] Kim JM, Min SK, Kim H, Kang HK, Jung SY, Lee SH, et al. Vacuolar-type $\mathrm{H}^{+}$-ATPasemediated acidosis promotes in vitro osteoclastogenesis via modulation of cell migration. Int $\mathrm{J}$ Mol Med 2007;19:393-400.

[28] Lee JH, Kim CS, Choi KH, Jung UW, Yun JH, Choi SH, et al. The induction of bone formation in rat calvarial defects and subcutaneous tissues by recombinant human BMP-2, produced in Escherichia coli. Biomaterials 2010;31:3512-9.

[29] Yeo IS, Han JS, Yang JH. Biomechanical and histomorphometric study of dental implants with different surface characteristics. J Biomed Mater Res B Appl Biomater 2008;87:303-11.

[30] Gruber HE. Adaptations of Goldner's Masson trichrome stain for the study of undecalcified plastic embedded bone. Biotech Histochem 1992;67:30-4.

[31] Yoshiki S, Umeda T, Kurahashi Y. An effective reactivation of alkaline phosphatase in hard tissues completely decalcified for light and electron microscopy. Histochemie 1972;29:296304.

[32] René A, Jackson RN. Gale encyclopedia of nursing and allied health, Infection control information on healthline. Detroit: The Gale Group Inc; 2002.

[33] Vukicevic S, Luyten FP, Kleinman HK, Reddi AH. Differentiation of canalicular cell processes in bone cells by basement membrane matrix components: regulation by discrete domains of laminin. Cell 1990;63:437-45. 
[34] Motlagh HN, Wrabl JO, Li J, Hilser VJ. The ensemble nature of allostery. Nature 2014;508:331-9.

[35] zur Nieden NI, Price FD, Davis LA, Everitt RE, Rancourt DE. Gene profiling on mixed embryonic stem cell populations reveals a biphasic role for $\beta$-catenin in osteogenic differentiation. Mol Endocrinol 2007;21:674-85.

[36] Takasaki W, Kajino Y, Kajino K, Murali R, Greene MI. Structure-based design and characterization of exocyclic peptidomimetics that inhibit TNF $\alpha$ binding to its receptor. Nat Biotechnol 1997;15:1266-70.

[37] Berke Z, Palmer S, Bergman T, Wester D, Svedmyr J, Linder S, et al. A short peptide eluted from the $\mathrm{H}-2 \mathrm{~K}^{\mathrm{b}}$ molecule of a polyomavirus-positive tumor corresponds to polyomavirus large $\mathrm{T}$ antigen peptide at amino acids 578 to 585 and induces polyomavirus-specific immunity. $\mathrm{J}$ Virol 1996;70:3093-7.

[38] Turksen K, Bhargava U, Moe HK, Aubin JE. Isolation of monoclonal antibodies recognizing rat bone-associated molecules in vitro and in vivo. J Histochem Cytochem 1992;40:1339-52.

[39] Min SK, Lee SC, Hong SD, Chung CP, Park WH, Min BM. The effect of a laminin-5-derived peptide coated onto chitin microfibers on re-epithelialization in early-stage wound healing. Biomaterials 2010;31:4725-30.

[40] Seo SY, Min SK, Bae HK, Roh D, Kang HK, Roh S, et al. A laminin-2-derived peptide promotes early-stage peripheral nerve regeneration in a dual-component artificial nerve graft. J Tissue Eng Regen Med 2013;7:788-800. 


\section{Figure Legends}

Fig. 1. The biologically active core binding sequence PPFEGCIWN (Ln2-LG3-P2-DN3) of Ln2-LG3P2 promotes cellular responses, including cell adhesion, spreading, and migration, and displays a broad cell-type specificity of adhesion. (A) The amino acid sequence of $\mathrm{N}$ - and C-terminal truncated peptides and the combinations of both for Ln2-LG3-P2. (B-D) Adhesion (B), spreading (C), and migration (D) of PC-12 cells induced by laminin, rLG3, and peptides. PC12 cells were seeded on plates coated with BSA (1\%), laminin $\left(1.1 \mu \mathrm{g} / \mathrm{cm}^{2}\right), \mathrm{rLG} 3\left(5.7 \mu \mathrm{g} / \mathrm{cm}^{2}\right)$, and synthetic peptides $(11.4$ $\mu \mathrm{g} / \mathrm{cm}^{2}$ ) for $1 \mathrm{~h}(\mathrm{~B})$ or $3 \mathrm{~h}(\mathrm{C})$ in serum-free medium. PC12 cells were seeded into the upper chamber of transwell filters coated with BSA (1\%), laminin $\left(1.6 \mu \mathrm{g} / \mathrm{cm}^{2}\right), \mathrm{rLG} 3\left(7.9 \mu \mathrm{g} / \mathrm{cm}^{2}\right)$, and synthetic peptides $\left(19.7 \mu \mathrm{g} / \mathrm{cm}^{2}\right)$ for $24 \mathrm{~h}(\mathrm{D})$. Data are expressed as a percentage of the value for cells seeded on laminin-coated plates for $3 \mathrm{~h}(\mathrm{C})$ or laminin-treated filters for $24 \mathrm{~h}(\mathrm{D})$. SP: scrambled peptide. ${ }^{*} p<$ 0.01 versus SP-treated control. (E) Cell adhesion to Ln2-LG3-P2-DN3 $\left(11.4 \mu \mathrm{g} / \mathrm{cm}^{2}\right)$ in normal human epidermal keratinocytes (NHEKs), normal human oral keratinocytes (NHOKs), normal human dermal fibroblasts (NHDFs), normal human oral fibroblasts (NHOFs), human Schwann cells, MC3T3-E1, NIH/3T3, and CV-1. Data are expressed as mean $\pm \operatorname{SD}(n=4)$.

Fig. 2. Characterization of human osteogenic cells differentiated from SKPs and cellular responses of osteogenic cells induced by laminin and peptides. (A) Photograph of monolayer cultures of SKPderived mesenchymal precursors differentiated for two weeks under osteogenic conditions and then stained for mineral deposits using alizarin red S. Bar $=100 \mu \mathrm{m}$. (B) Expression of osteogenic markers, including alkaline phosphatase (ALP), osteonectin, type I collagen, bone sialoprotein (BSP), RUNX2, and osteocalcin was measured by qRT-PCR. (C) Photographs of osteogenic cells adhering to the culture plates treated with BSA (1\%), laminin $\left(1.3 \mu \mathrm{g} / \mathrm{cm}^{2}\right)$, and synthetic peptides $\left(13.2 \mu \mathrm{g} / \mathrm{cm}^{2}\right)$ for 3 h. Bar $=100 \mu \mathrm{m}$. (D and E) Adhesion (D) and spreading (E) of osteogenic cells induced by BSA (1\%), laminin $\left(1.3 \mu \mathrm{g} / \mathrm{cm}^{2}\right)$, and synthetic peptides $\left(13.2 \mu \mathrm{g} / \mathrm{cm}^{2}\right)$. SP: scrambled peptide. ${ }^{*} p<0.01$. Data are 
expressed as mean $\pm \mathrm{SD}(n=4)$. (F) ALP activity of human osteogenic cells treated with rhBMP-2 and Ln2-LG3-P2-DN3. Human osteogenic cells $\left(2 \times 10^{5}\right.$ cells/well $)$ were cultured either on 6-well plates in serum-free medium supplemented with $300 \mathrm{ng} / \mathrm{ml}$ rhBMP-2 or on Ln2-LG3-P2-DN3-treated plates in serum-free medium for $5 \mathrm{~d}$. Data are expressed as mean $\pm \operatorname{SD}(n=4) .{ }^{*} p<0.01$.

Fig. 3. Representative photomicrographs of inflammatory responses to synthetic peptide-treated absorbable collagen sponges in rats. H\&E staining of wounds from Ln2-LG3-P2- (A) and Ln2-LG3P2-DN3-treated (B) collagen sponges in rats $3 \mathrm{~d}$ after injury. Insets are magnified images of the rectangles indicated. Data are expressed as mean $\pm \mathrm{SD}(n=4)$. Bars $=100 \mu \mathrm{m}$.

Fig. 4. Effects of Ln2-LG3-P2-DN3 on in vivo bone regeneration. Critical-size rat calvarial defects were implanted with absorbable collagen sponges treated with BMP-2 $\left(4 \mu \mathrm{g} / \mathrm{cm}^{2}\right)$, scrambled peptide $\left(\mathrm{SP} ; 1.0 \mathrm{mg} / \mathrm{cm}^{2}\right)$, or Ln2-LG3-P2-DN3 $\left(0.5\right.$ and $\left.1.0 \mathrm{mg} / \mathrm{cm}^{2}\right)$. Three-dimensional $\mu \mathrm{CT}$ images (A), bone recovery rate (B), and bone volume/tissue volume rate $(\mathrm{C})$ in the region of defects, and Masson's trichrome staining of rat calvarial sections to visualize mineralized bone (D) and calvarial thickness (E) at three weeks after transplantation. In panel (D), insets are magnified images of the rectangles indicated. ${ }^{*} p<0.01 ;{ }^{* *} p<0.05$.

Fig. 5. Cellular responses, osteogenic marker gene expression, and ALP activity of osteogenic cells plated onto the modified Ti surfaces. SEM micrographs (A) and levels of cell adhesion (B) and spreading (C) of human osteogenic cells plated for $1 \mathrm{~h}(\mathrm{~B})$ and $3 \mathrm{~h}(\mathrm{~A}$ and $\mathrm{C}$ ) onto pure Ti surfaces treated with BSA (1\%), laminin $\left(1.4 \mu \mathrm{g} / \mathrm{cm}^{2}\right)$, scrambled peptide (SP), Ln2-LG3-P2, or Ln2-LG3-P2DN3 $\left(14.3 \mu \mathrm{g} / \mathrm{cm}^{2}\right)$. Bars $=50 \mu \mathrm{m}$. (D) Induction of osteogenic marker genes in osteogenic cells seeded onto peptide-treated Ti surfaces. Human osteogenic cells $\left(2 \times 10^{5}\right.$ cells/well $)$ were seeded onto Ti discs (20 mm in diameter, $0.5 \mathrm{~mm}$ thick) treated with SP, Ln2-LG3-P2, or Ln2-LG3-P2-DN3 (14.3 $\mu \mathrm{g} / \mathrm{cm}^{2}$ ), which were placed on 12-well culture plates and cultured for $3 \mathrm{~d}$ in serum-free medium. 
Expression of osteogenic markers, including osteonectin, type I collagen, RUNX2, and osteocalcin, was determined by qRT-PCR. (E) ALP activity of human osteogenic cells seeded onto peptide-treated Ti surfaces. Human osteogenic cells $\left(8 \times 10^{5}\right.$ cells/well $)$ were seeded onto Ti discs $(50 \mathrm{~mm}$ in diameter, $0.5 \mathrm{~mm}$ thick) coated with SP, Ln2-LG3-P2, or Ln2-LG3-P2-DN3 $\left(14.3 \mu \mathrm{g} / \mathrm{cm}^{2}\right)$, which were placed on 60-mm culture dishes and cultured for $1 \mathrm{~d}$ in serum-free medium. Ti: pure Ti surface. Data are expressed as mean $\pm \operatorname{SD}(n=4) .{ }^{*} p<0.01,{ }^{* *} p<0.05$.

Fig. 6. Light microscopy images of longitudinal sections and staining for collagen and ALP of longitudinal sections of Ti implants from Ln2-LG3-P2- and Ln2-LG3-P2-DN3-treated Ti implantinserted rabbit tibiae. (A) $\mathrm{H} \& \mathrm{E}$ staining of the wounds with the pure Ti implant and the scrambled peptide (SP; $\left.1 \mathrm{mg} / \mathrm{cm}^{2}\right)$-, Ln2-LG3-P2 $\left(1 \mathrm{mg} / \mathrm{cm}^{2}\right)$-, and Ln2-LG3-P2-DN3 (1 mg/cm²)-treated Ti implants inserted into rabbit tibiae at one, two, and four weeks. Insets are the magnified images of the squares indicated. (B) BIC ratio in wounds from pure Ti implants and SP-, Ln2-LG3-P2- and Ln2LG3-P2-DN3-treated Ti implants in rabbit tibiae at one, two, and four weeks. Data are expressed as mean $\pm \operatorname{SD}(n=3) .{ }^{*} p<0.01,{ }^{* *} p<0.05$. (C and D) Modified Goldner's Masson trichrome staining (C) and ALP histochemistry (D) of the wounds of pure Ti implants and SP-, Ln2-LG3-P2-, and Ln2-LG3P2-DN3-treated Ti implants in rabbit tibiae at one, two, and four weeks. Blue arrowheads (D) indicate ALP staining of osteoblasts. Ti only, pure Ti implant; SP, SP-treated Ti implant; Ln2-LG3-P2, Ln2LG3-P2-treated Ti implant; Ln2-L 'G3-P2-DN3, Ln2-LG3-P2-DN3-treated Ti implant. Bars $=100 \mu \mathrm{m}$.

Fig. 7. A hypothetical diagram for the intracellular event-provoking mechanism of the lamininderived bioactive peptides. The black horizontal line presents the threshold conformational Gibbs free energy level to turn on the intracellular events. The light bulbs (black arrowheads) beneath PKC $\delta$ s display the degree of activation. The lower the energy level is, the more the intracellular events are activated. There are two core amino acid sequences from the human laminin $\alpha 2$ chain found to bind to cellular transmembrane proteins, PPFEGCIWN in this study and DLTIDDSYWYRI in another. There 
is equilibrium between the inactive state and the active states without either of the peptides (the uppermost row). Peptide binding to a transmembrane protein stabilizes the conformation, resulting in equilibrium shift to increase the probabilities of the active states (the second and third rows from the top). The most stable conformation occurs in the highest frequency, when the original laminin binds to the receptors (the bottom right); both of the peptides attach to the binding sites. Other parts of the laminin are considered to stabilize the conformation more. This figure is drawn assuming that the energy level of the PPFEGCIWN binding form is lower than that of the DLTIDDSYWYRI binding form, which has not yet been investigated. The protein designated as (?) remains unknown. 


\section{Supplemental material}

Suppl. Fig. 1. Animal surgeries were performed to install the investigated implants. (A) Representative photograph after implant placement in the rabbit tibia. Two implants were inserted in the right tibia. (B) A schematic diagram explaining the position of the inserted implants. The interimplant distance was about $8-10 \mathrm{~mm}$ from center to center. (C) Schematic diagrams showing the arrangement of the implant groups. Control, pure Ti implant; SP, SP-treated Ti implant; Ln2-LG3-P2, Ln2-LG3-P2-treated Ti implant; Ln2-LG3-P2-DN3, Ln2-LG3-P2-DN3-treated Ti implant.

Suppl. Fig. 2. Cell adhesion, spreading, and migration of osteoblast-like cells seeded onto the culture plates treated with laminin, scrambled peptide (SP), Ln2-LG3-P2, and Ln2-LG3-P2-DN3. (A) Photographs of osteoblast-like HOS and MG-63 cells adhering to the culture plates treated with BSA (1\%), laminin $\left(1.3 \mu \mathrm{g} / \mathrm{cm}^{2}\right)$, SP, Ln2-LG3-P2, and Ln2-LG3-P2-DN3 $\left(13.2 \mu \mathrm{g} / \mathrm{cm}^{2}\right)$ for $3 \mathrm{~h}$. Bar $=100$ $\mu \mathrm{m}$. (B and C) Adhesion (B) and spreading (C) of osteoblast-like HOS and MG-63 cells seeded on plates treated with BSA, laminin, and synthetic peptides for $1 \mathrm{~h}$ (B) or $3 \mathrm{~h}$ (C). (D) Migration of osteoblast-like HOS and MG-63 cells seeded into the upper chamber of transwell filters treated with BSA $(1 \%)$, laminin $\left(1.6 \mu \mathrm{g} / \mathrm{cm}^{2}\right)$, and synthetic peptides $\left(19.7 \mu \mathrm{g} / \mathrm{cm}^{2}\right)$ for $24 \mathrm{~h}$. Data are expressed as mean $\pm \operatorname{SD}(n=4) .{ }^{*} p<0.01$.

Suppl. Fig. 3. Cell adhesion and spreading of osteoblast-like cells plated onto the modified Ti surfaces. SEM micrographs (A) and levels of cell adhesion (B) and spreading (C) of osteoblast-like HOS and MG-63 cells plated for $1 \mathrm{~h}(\mathrm{~B})$ and $3 \mathrm{~h}$ (A and C) onto BSA (1\%)-, laminin $\left(1.4 \mu \mathrm{g} / \mathrm{cm}^{2}\right)-$, scrambled peptide (SP)-, Ln2-LG3-P2-, and Ln2-LG3-P2-DN3 $\left(14.3 \mu \mathrm{g} / \mathrm{cm}^{2}\right)$-treated pure Ti surfaces. Data are expressed as mean $\pm \mathrm{SD}(n=4)$. Bars $=50 \mu \mathrm{m} .{ }^{*} p<0.01$. 
Fig. 1

A

\begin{tabular}{lc}
\hline \multicolumn{1}{c}{ Peptide } & Sequence \\
\hline Ln2-LG3-P2 & RNIPPFEGCIWN \\
Ln2-LG3-P2-DN1 & NIPPFEGCIWN \\
Ln2-LG3-P2-DN2 & IPPFEGCIWN \\
Ln2-LG3-P2-DN3 & PPFEGCIWN \\
Ln2-LG3-P2-DN4 & PFEGCIWN \\
Ln2-LG3-P2-DN5 & FEGCIWN \\
Ln2-LG3-P2-DC1 & RNIPPFEGCIW \\
Ln2-LG3-P2-DC2 & RNIPPFEGCI \\
Ln2-LG3-P2-DC3 & RNIPPFEGC \\
Ln2-LG3-P2-DN3-DC1 & PPFEGCIW \\
Ln2-LG3-P2-DN3-DC2 & PPFEGCI \\
Ln2-LG3-P2-DN3-DC3 & PPFEGC \\
Ln2-LG3-P2-DN3-DC4 & PPFEG \\
Ln2-LG3-P2-DN3-DC5 & PPFE \\
Ln2-LG3-P2-DN3-DC6 & PPF
\end{tabular}

C

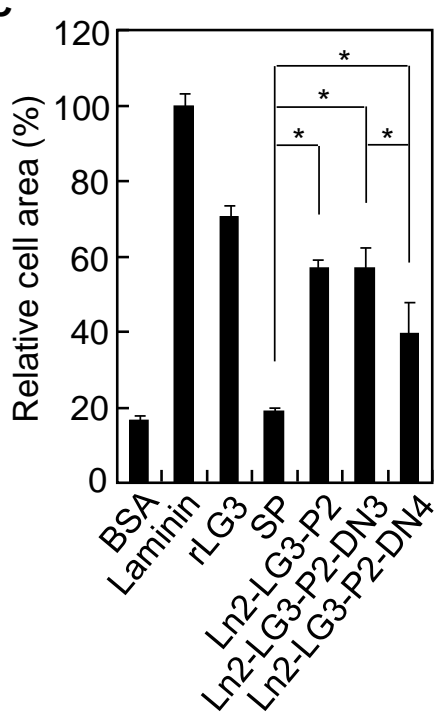

D

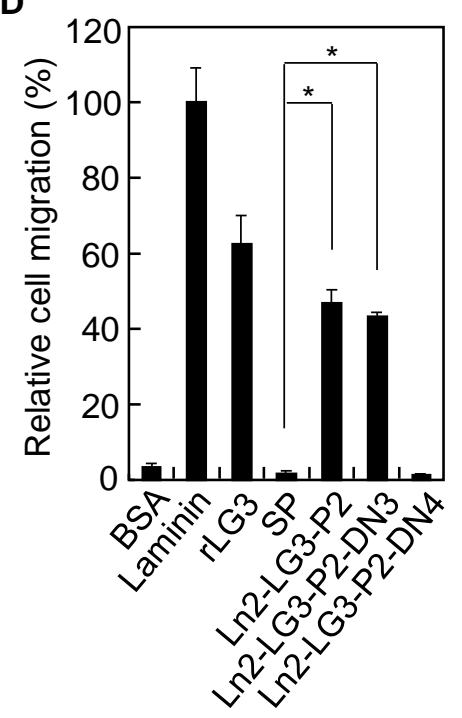

B

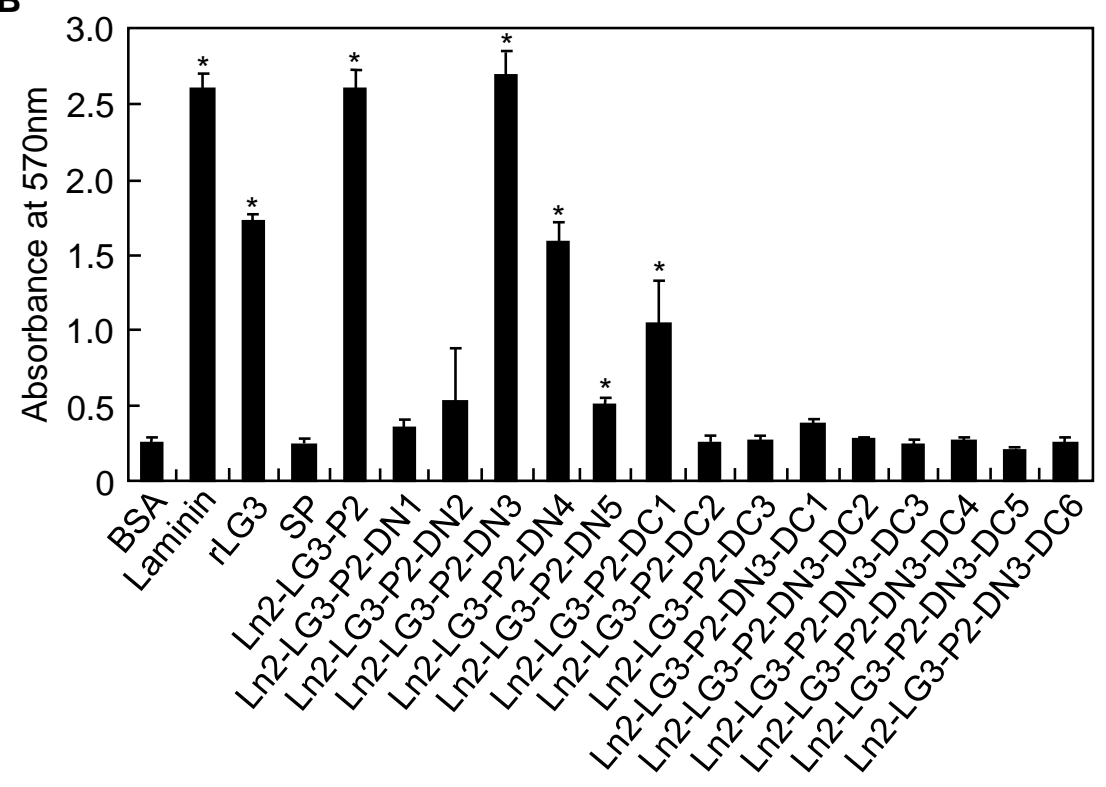

E

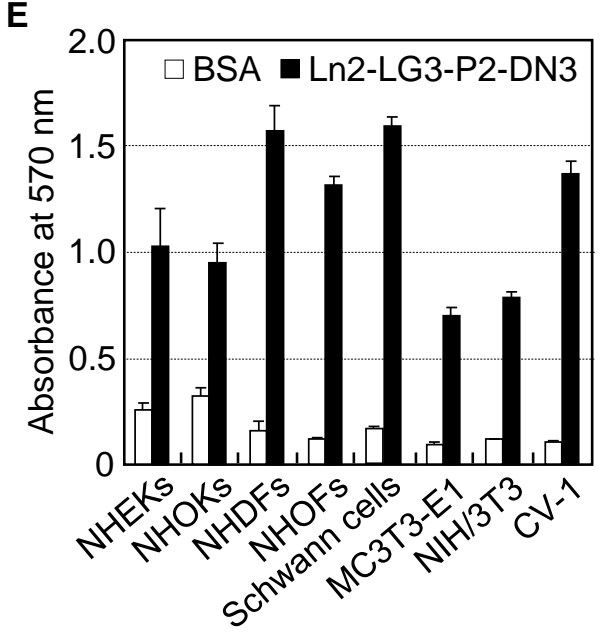


Fig. 2
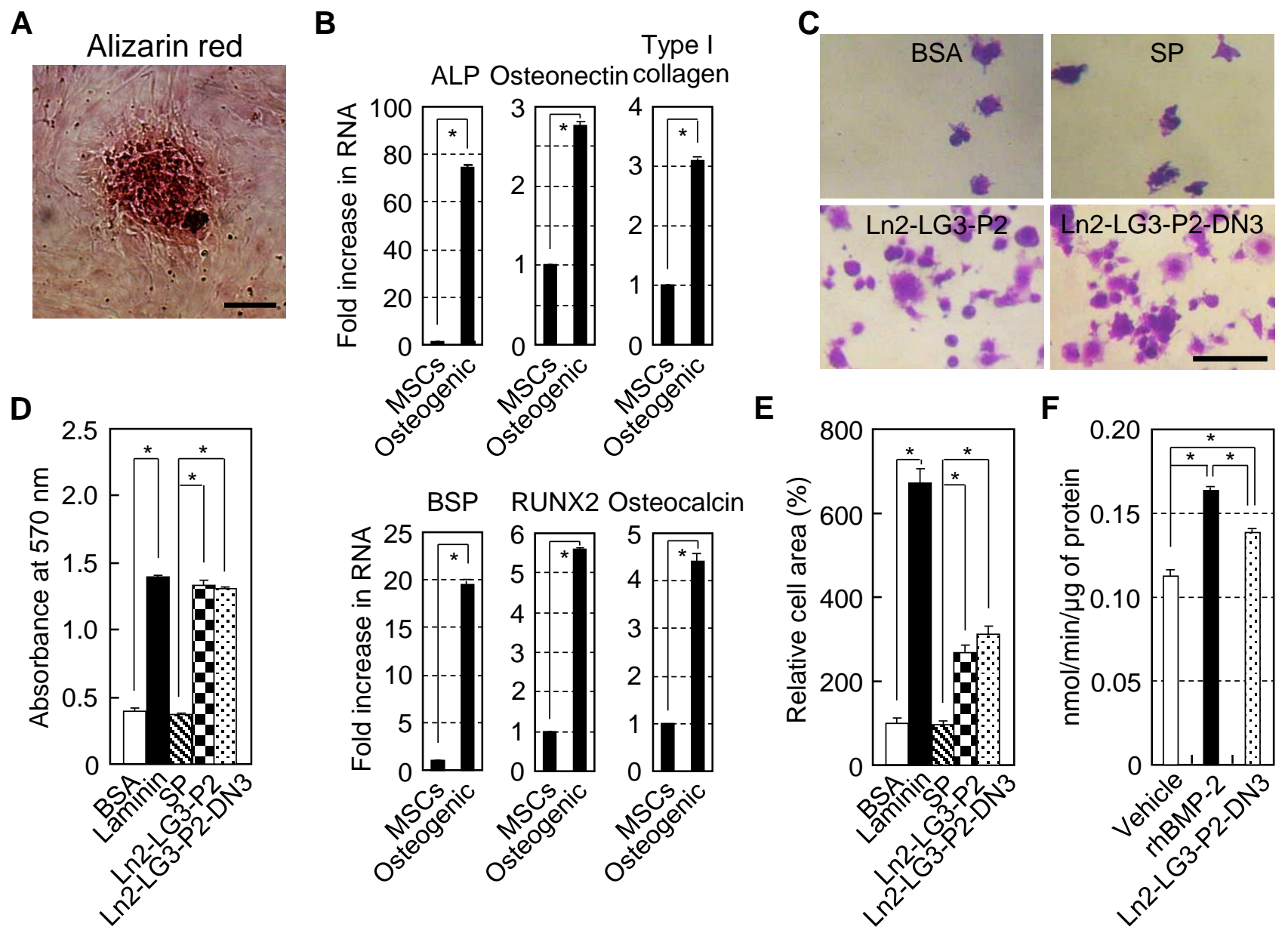
Fig. 3

A
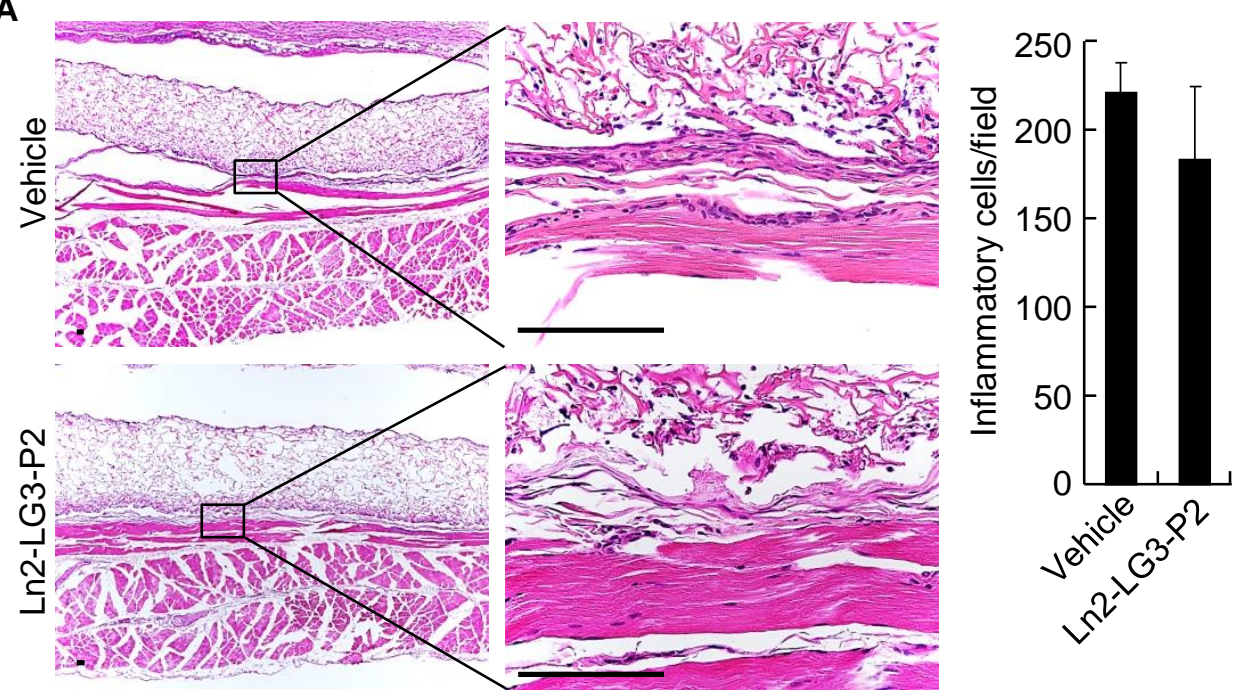

B
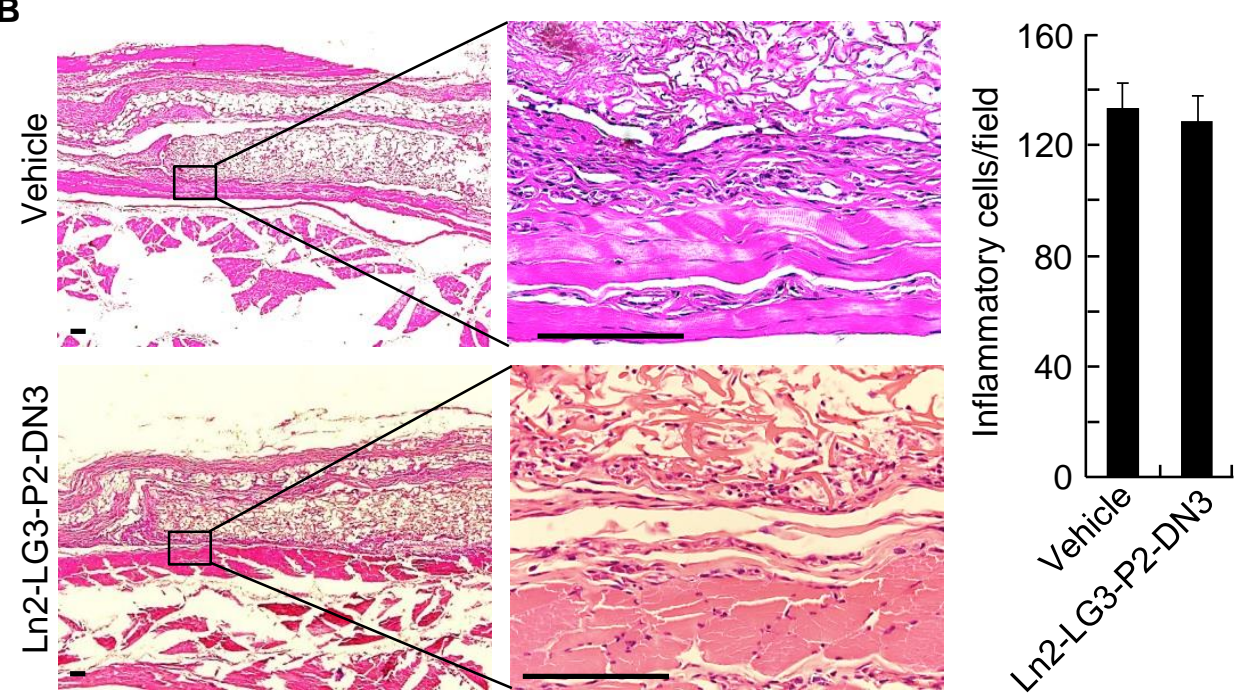
Fig. 4

A
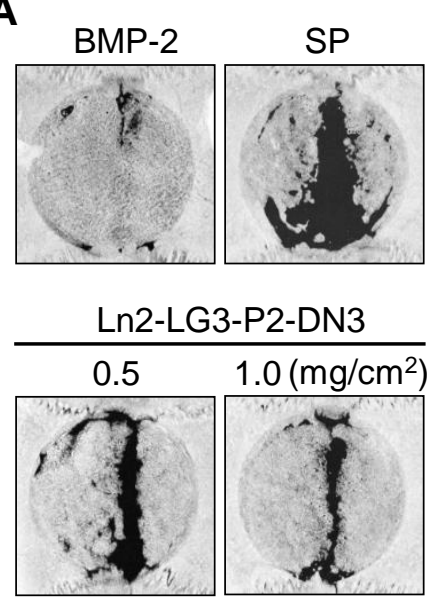

D

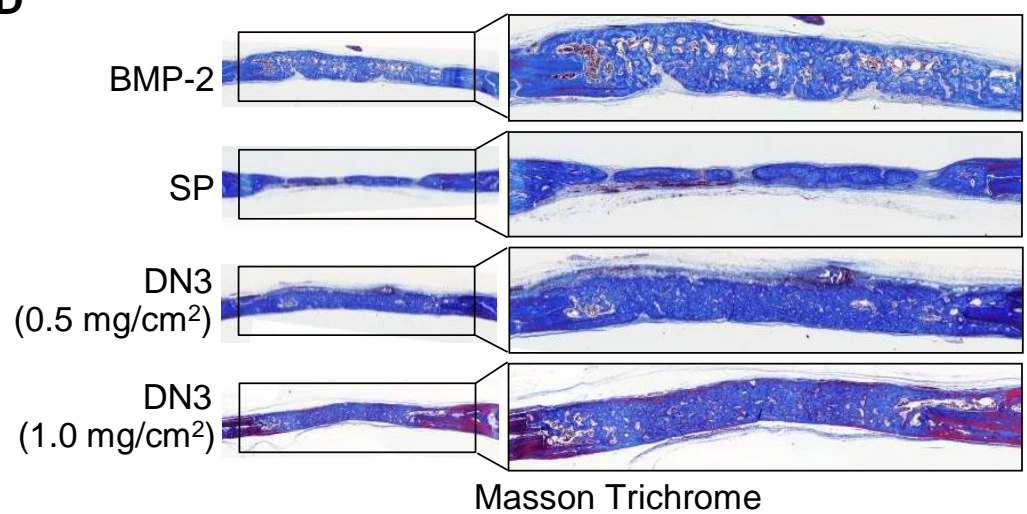

B

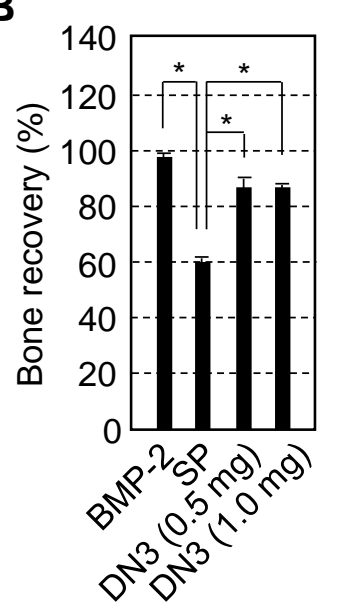

C

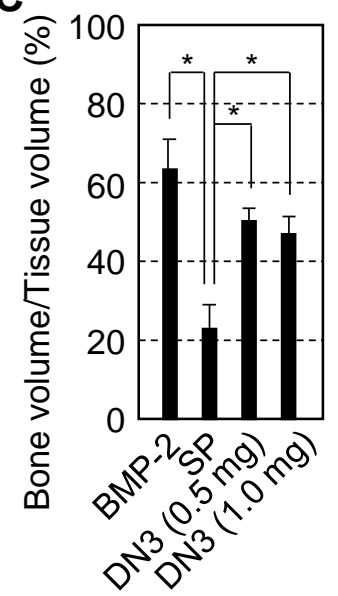

E

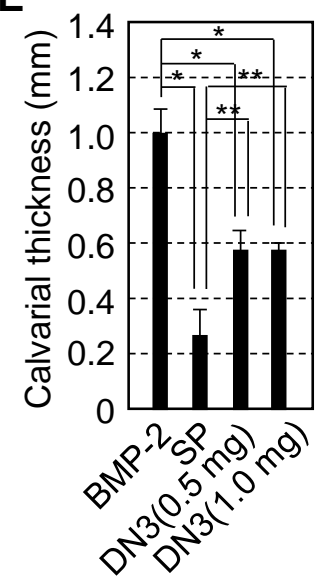


Fig. 5

A

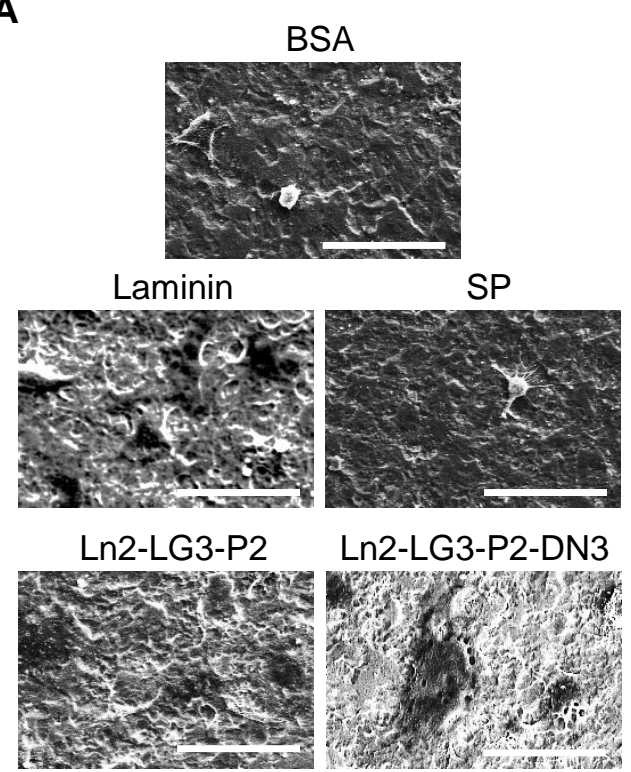

B
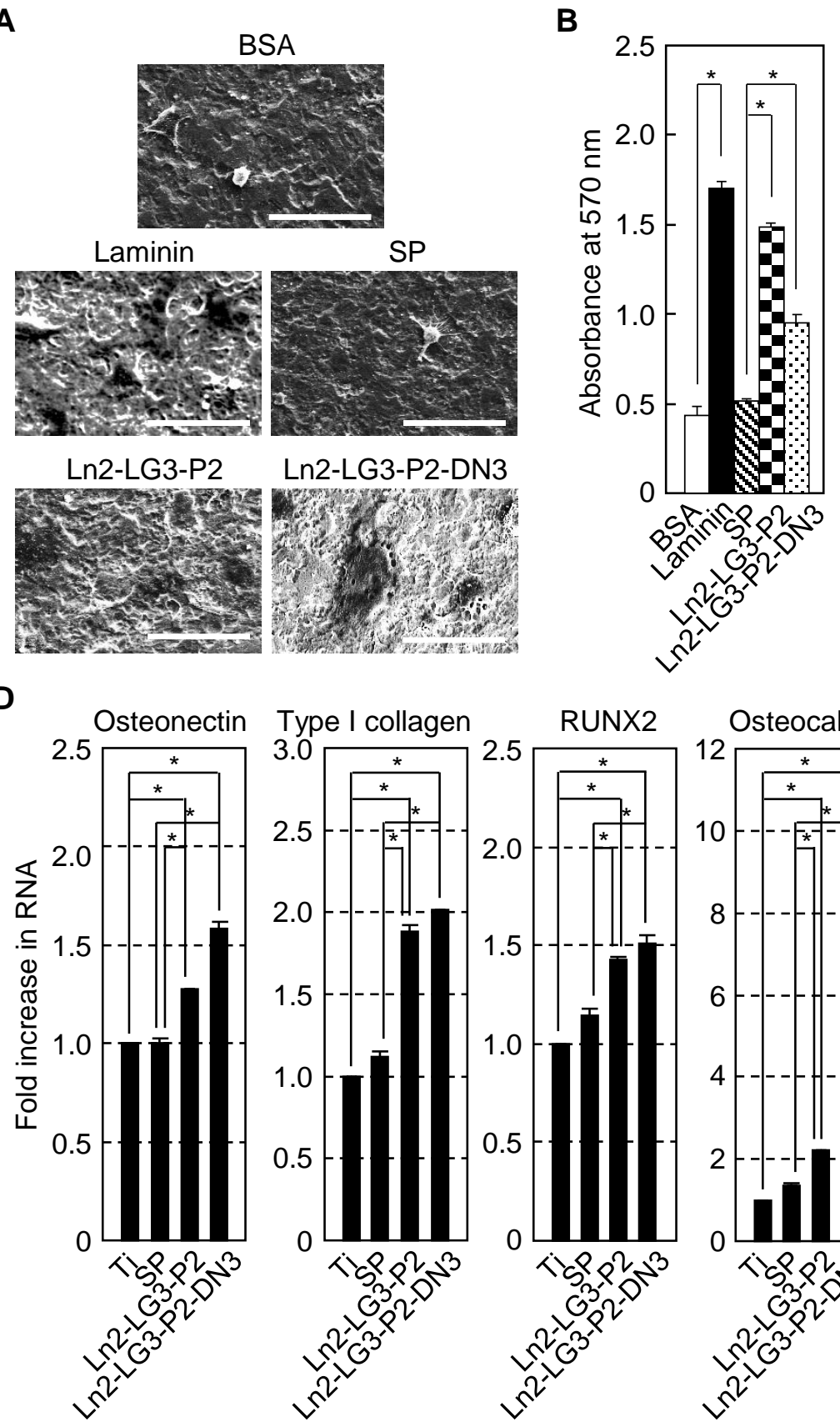

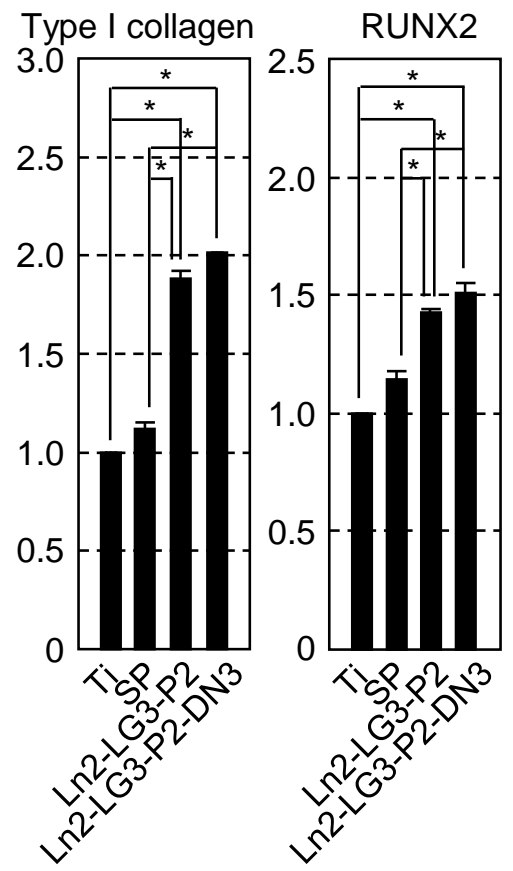

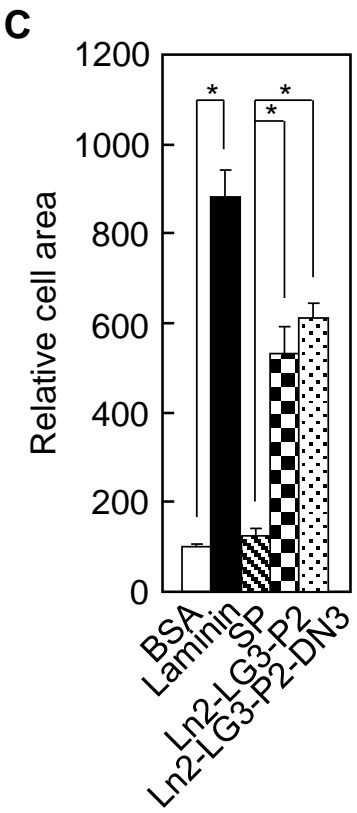

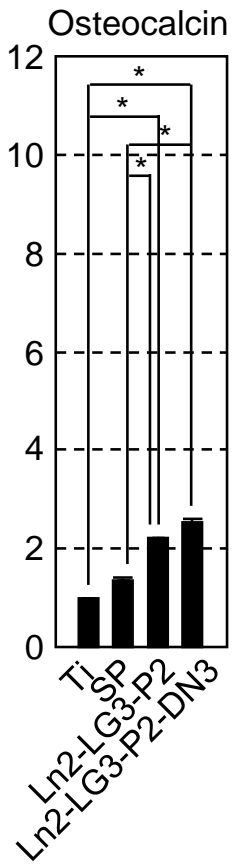

E

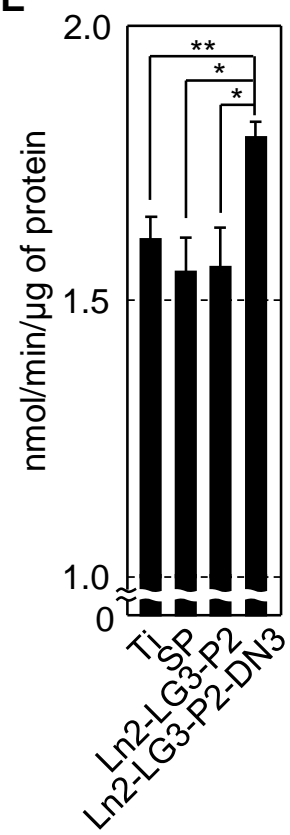


Fig. 6

A
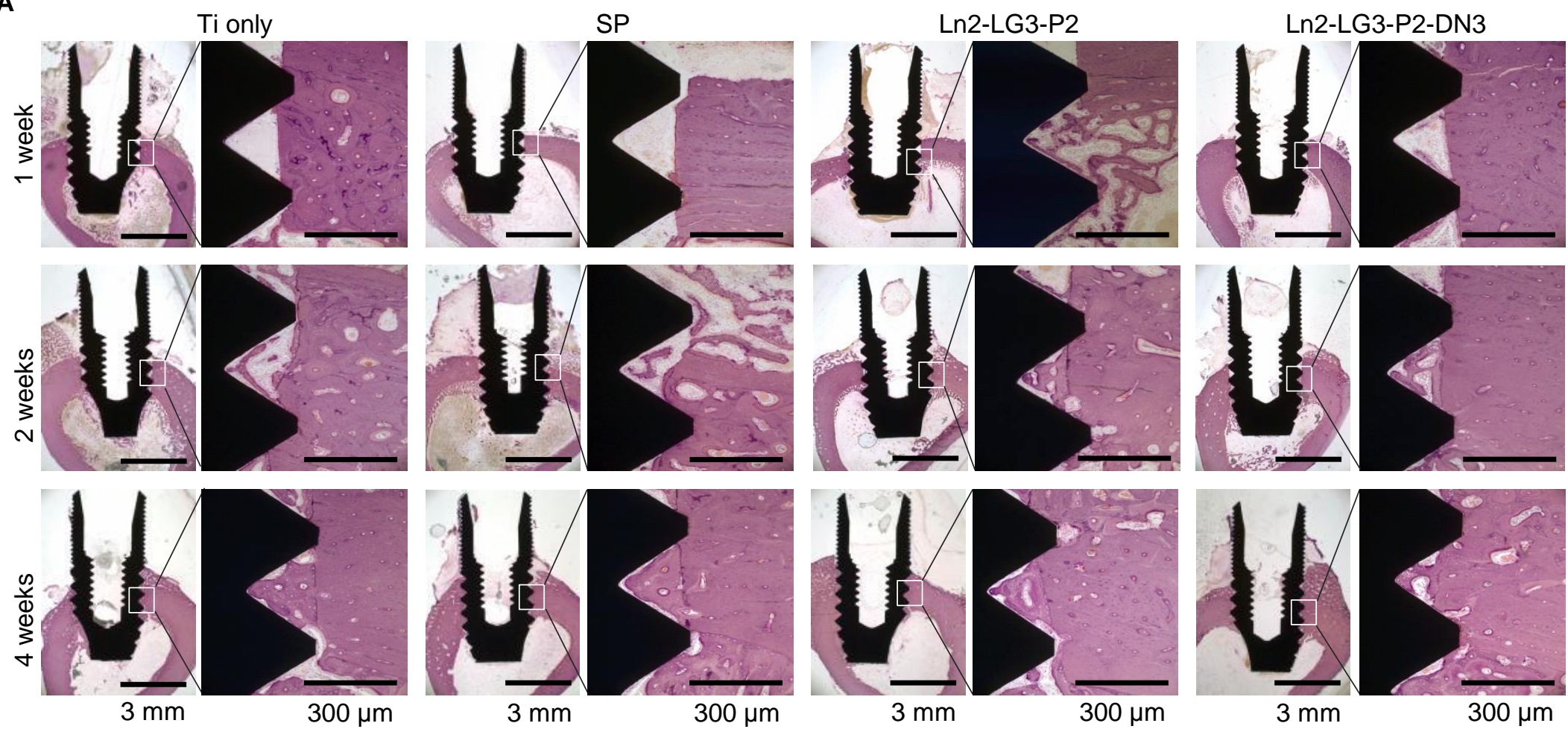

B

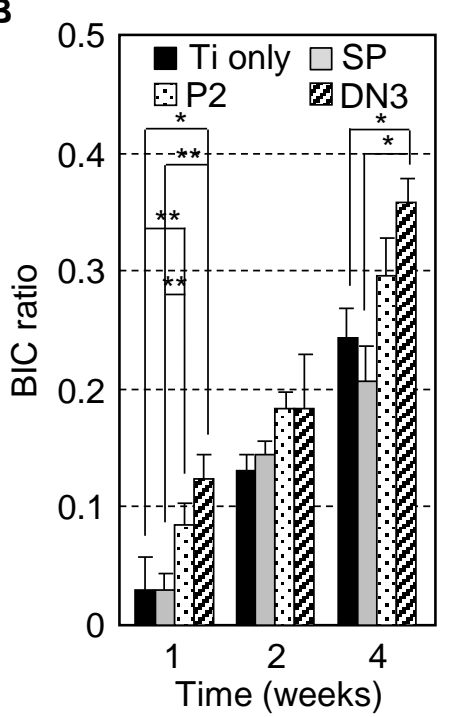


Fig. 6
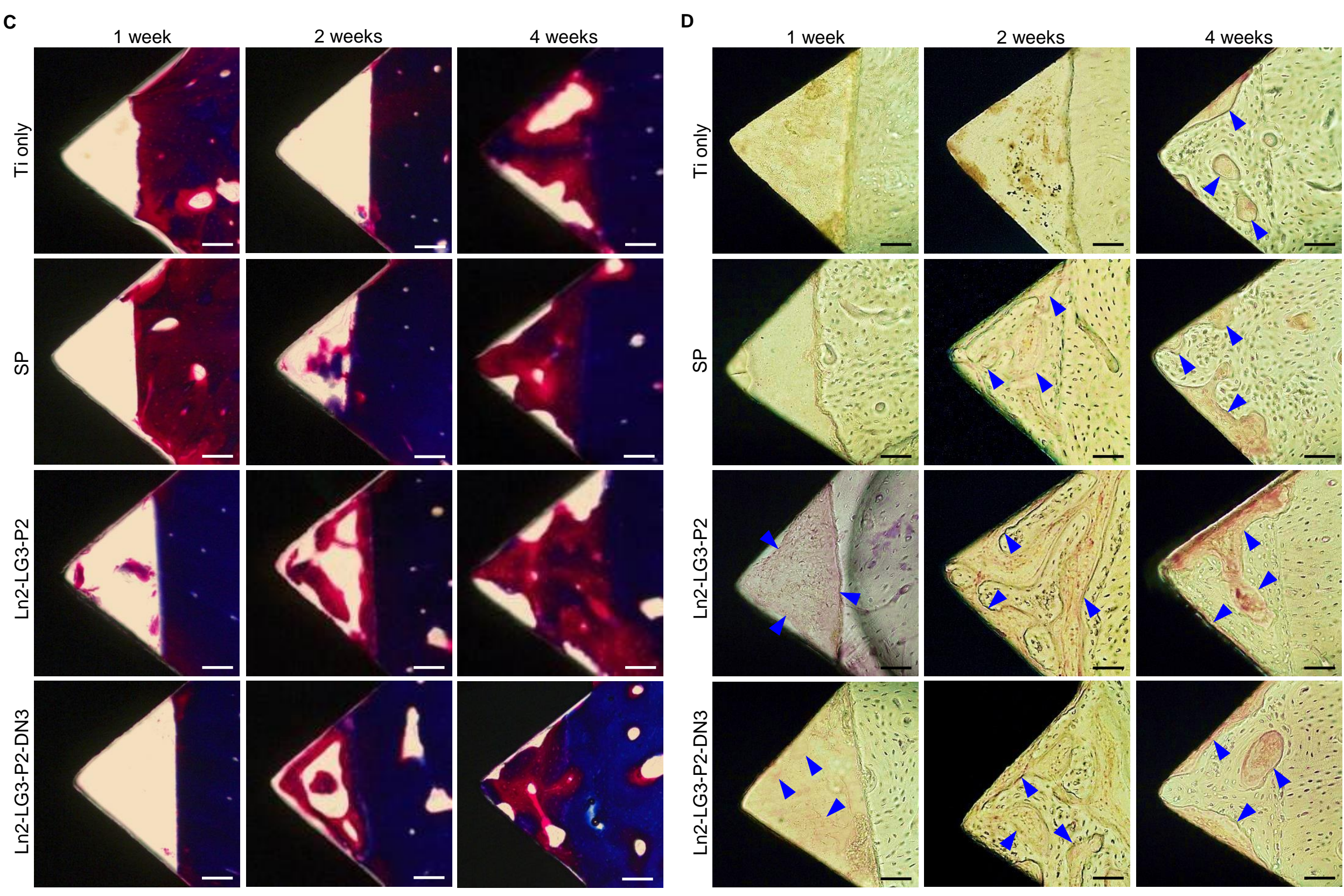
Fig. 7

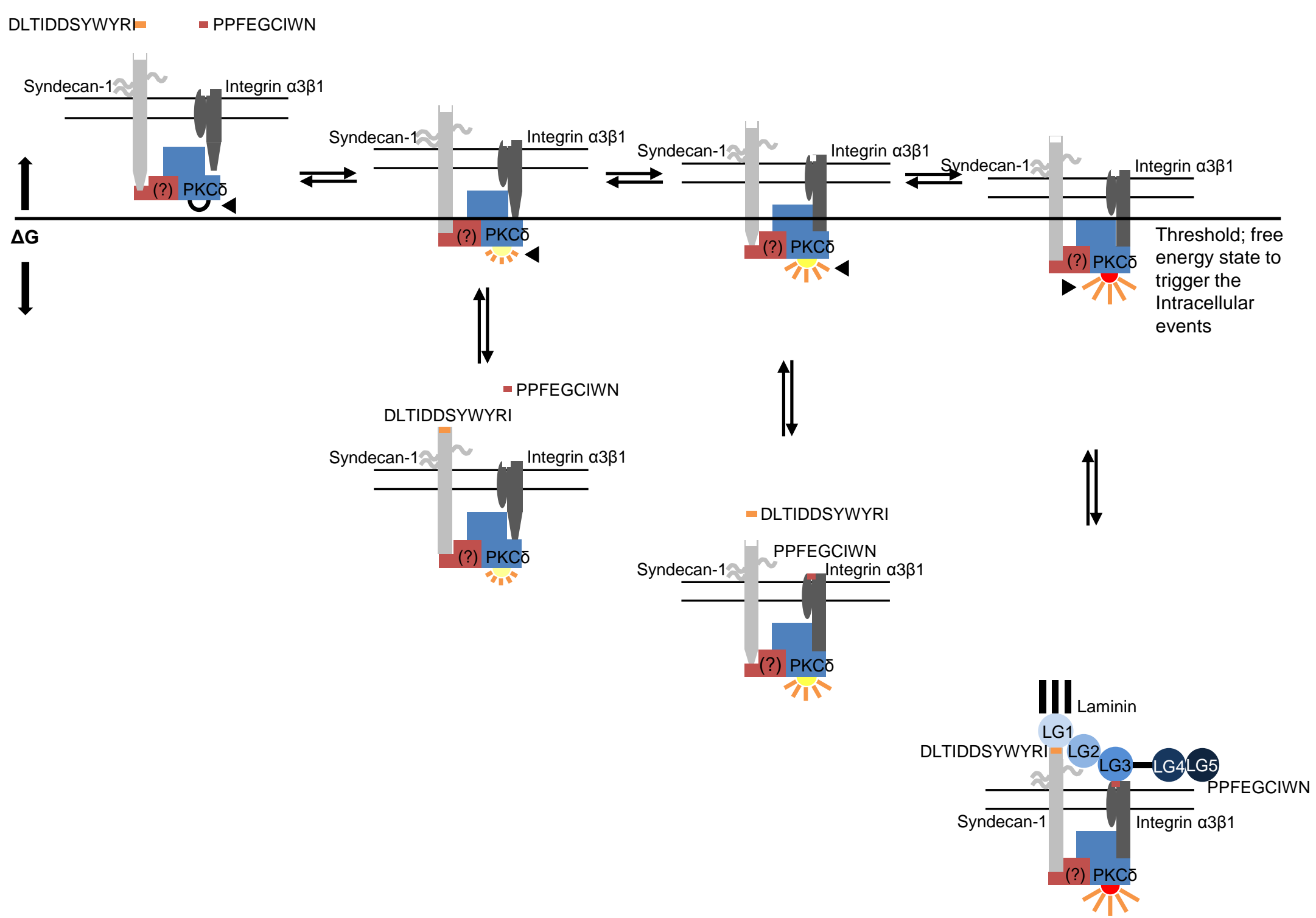

